Chemical Technology

Division

Chemical Technology

Division

Chemical Tecinnology

Division

Chemical Technology

Division

Chemical Technology

Division

Chemical Technology

Division
chnology

Division

Chemical Technology

Division

Chemical Technology

Division

Chemical Technology

RECEIVED

DEC 051995

\title{
OSTI \\ Extraction of Long-lived Radionuclides from Caustic Hanford Tank Waste Supernatants
}

Division

Chemical Technology

Division

Chemicen Technology

Diyision

Chemical Technology

Division

Chemical Technology

Division

Chemical Technology

Division

Chemical Technology

Division

Chemical Technology

Division

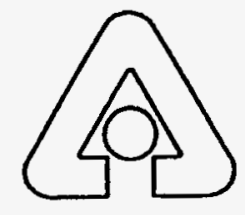

Argonne National Laboratory, Argonne, Illinois 60439

operated by The University of Chicago

for the United States Department of Energy under Contract W-31-109-Eng-38

Chemical Technology

Division

Chemical Technology

Division

Chemical Technology

Division

Chemical Technology

by D. J. Chaiko, C. J. Mertz, Y. Vojta, J. L. Henriksen, R. Neff, and M. Takeuchi

Division 
Argonne National Laboratory, with facilities in the states of Illinois and Idaho, is owned by the United States government, and operated by The University of Chicago under the provisions of a contract with the Department of Energy.

\section{DISCLAIMER}

This report was prepared as an account of work sponsored by an agency of the United States Government. Neither the United States Government nor any agency thereof, nor any of their employees, makes any warranty, express or implied, or assumes any legal liability or responsibility for the accuracy, completeness, or usefulness of any information, apparatus, product, or process disclosed, or represents that its use would not infringe privately owned rights. Reference herein to any specific commercial product, process, or service by trade name, trademark, manufacturer, or otherwise, does not necessarily constitute or imply its endorsement, recommendation, or favoring by the United States Government or any agency thereof. The views and opinions of authors expressed herein do not necessarily state or reflect those of the United States Government or any agency thereof.

Reproduced from the best available copy.

Available to DOE and DOE contractors from the

Office of Scientific and Technical Information

P.O. Box 62

Oak Ridge, TN 37831

Prices available from (615) 576-8401

Available to the public from the

National Technical Information Service

U.S. Department of Commerce

5285 Port Royal Road

Springfield, VA 22161 


\section{DISCLAIMER}

\section{Portions of this document may be illegible in electronic image products. Images are produced from the best available original document.}


Distribution Category:

Nuclear Waste Management

UC-510

\author{
ANL-95/39 \\ ARGONNE NATIONAL LABORATORY \\ 9700 South Cass Avenue \\ Argonne, IL 60439

\section{EXTRACTION OF LONG-LIVED RADIONUCLIDES \\ FROM CAUSTIC HANFORD TANK WASTE SUPERNATANTS} \\ by \\ D.J. Chaiko, C.J. Mertz, \\ Y. Vojta, J.L. Henriksen, R. Neff, and M. Takeuchi
}

Chemical Technology Division

July 1995

DISTRIBUTION OF THIS DOCUMENT IS IIM! I ITT:

DISTRIBUTION OF THIS DOCUMENT IS UM!

DISTRIBUTION OF THIS DOCUMENT IS UNLLATTED $w^{N}$ 


\section{PREFACE}

The work described in this report was carried out during 1993-1994. The portions of the study involving PEG-2000 were conducted at Northern Ilinois University through a subcontract with Dr. Robin Rogers. Subsequent to the completion of this project, pertechnetate partition data were published in (1) R.D. Rogers, A.H. Bond, C.B. Bauer, J. Zhang, S.D. Rein, R.R. Chomko, and D.M. Roden, Solvent Extr. Ion Exch. 13, 689 (1995), (2) R.D. Rogers, J. Zhang, A.H. Bond, C.B. Bauer, M.L. Jezl, and D.M. Roden, Solvent Extr. Ion Exch. 13, 665 (1995), and (3) R.D. Rogers, A.H. Bond, C.B. Bauer, J. Zhang, M.L. Jezl, D.M. Roden, S.D. Rein, and R.R. Chomko, in Aqueous Biphasic Separations: Biomolecules to Metal Ions, R.D. Rogers and M.A. Eiteman, Eds., Plenum, New York, pp. 1-20 (1995). 


\section{CONTENTS}

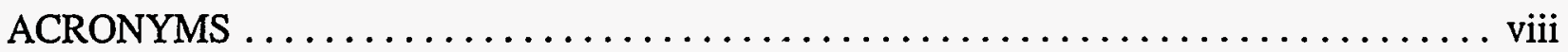

ABSTRACT $\ldots \ldots \ldots \ldots \ldots \ldots \ldots \ldots \ldots \ldots \ldots \ldots \ldots \ldots \ldots \ldots \ldots \ldots \ldots \ldots \ldots \ldots \ldots \ldots$

SUMMARY AND CONCLUSIONS $\ldots \ldots \ldots \ldots \ldots \ldots \ldots \ldots \ldots \ldots \ldots \ldots \ldots \ldots \ldots \ldots \ldots \ldots$

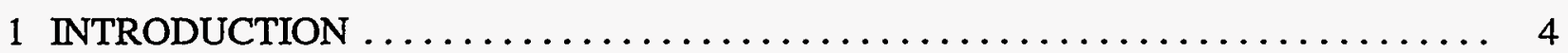

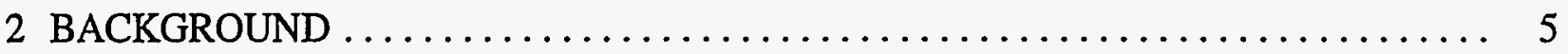

3 AQUEOUS BIPHASE FORMATION WITH POLYETHYLENE GLYCOLS

AND TANK WASTE SIMULANTS $\ldots \ldots \ldots \ldots \ldots \ldots \ldots \ldots \ldots \ldots \ldots, 9$

4 POLYETHYLENE GLYCOL EXTRACTION SYSTEMS $\ldots \ldots \ldots \ldots \ldots \ldots \ldots \ldots$

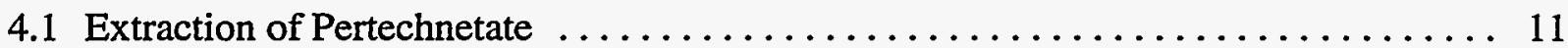

-4.2 Partitioning Behavior of Major Tank Waste Constituents ............... 13

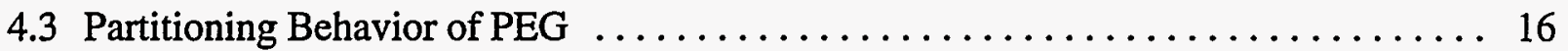

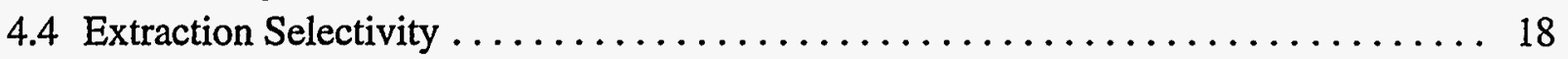

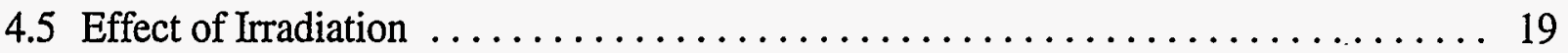

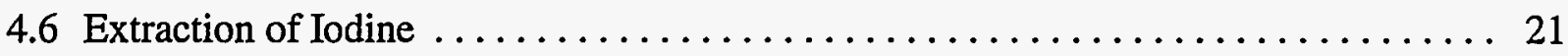

4.7 Back Extraction of Radionuclides from PEG Phases $\ldots \ldots \ldots \ldots \ldots \ldots \ldots . \ldots 23$

5 IMMOBILIZED POLYETHYLENE GLYCOL SYSTEMS $\ldots \ldots \ldots \ldots \ldots \ldots \ldots 24$

6 POLYPROPYLENE GLYCOL EXTRACTION SYSTEMS $\ldots \ldots \ldots \ldots \ldots \ldots \ldots$

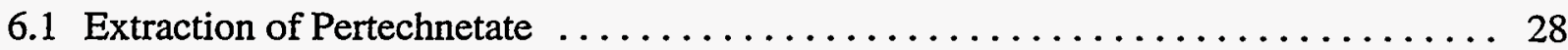

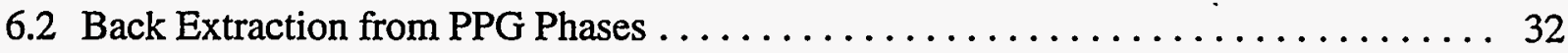

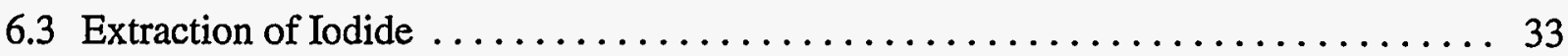

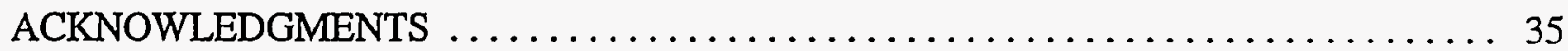

APPENDIX A: EXPERIMENTAL PROCEDURES $\ldots \ldots \ldots \ldots \ldots \ldots \ldots \ldots \ldots \ldots$

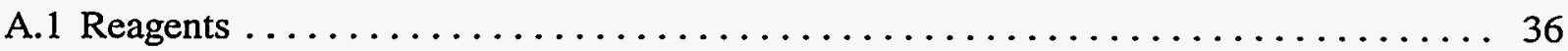

A.2 Preparation of Waste Simulants . . . . . . . . . . . . . . . . . . . . 36

A.3 Measurement of Phase Diagrams and Phase Separation Rates ............ 40 


\section{CONTENTS (Cont.)}

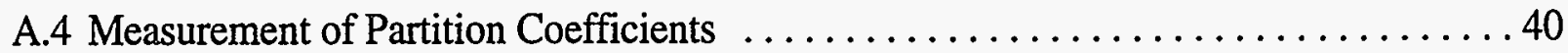

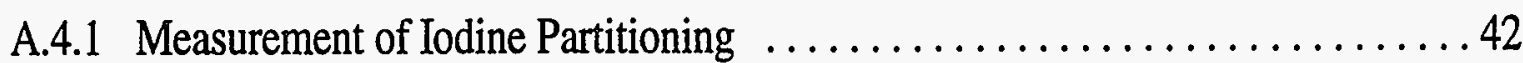

A.4.2 Partitioning to Immobilized PEGs $\ldots \ldots \ldots \ldots \ldots \ldots \ldots \ldots \ldots \ldots . \ldots \ldots$

APPENDIX B: POLYMER IRRADIATION STUDIES $\ldots \ldots \ldots \ldots \ldots \ldots \ldots \ldots . \ldots 4$

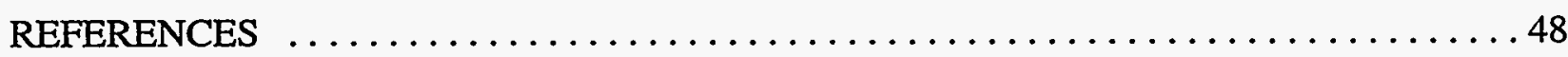

\section{TABLES}

1 Extraction of Pertechnetate from Waste Simulants by PEG-1500 and

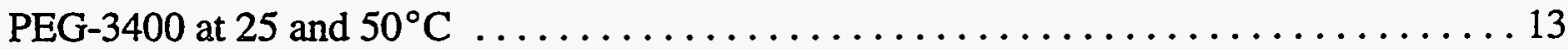

2 Extraction of Pertechnetate from SY-101 Waste Simulants as a Function

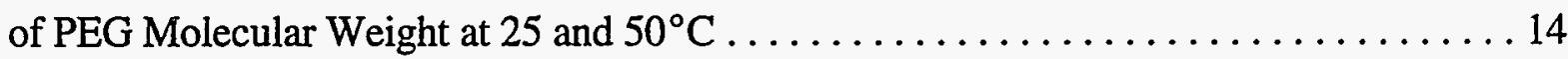

3 Partition Coefficients of Constituent Electrolytes in Tank Waste Simulants at $25^{\circ} \mathrm{C} \ldots \ldots 20$

4 Partition Coefficients of Constituent Electrolytes in Tank Waste Simulants at $50^{\circ} \mathrm{C} \ldots \ldots 20$

5 Separation of Pertechnetate from Other Waste Simulant Anions

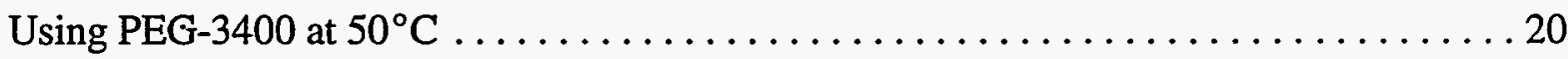

6 Extraction of Pertechnetate in the Presence of $\mathrm{U}(\mathrm{VI})$ at $50^{\circ} \mathrm{C} \ldots \ldots \ldots \ldots \ldots \ldots 21$

7 Effect of 14 Mrad of Gamma Radiation on the Partitioning of PEG-3400 . . . . . . 22

8 Effect of Gamma Radiation on the Extraction of Pertechnetate from Simulated

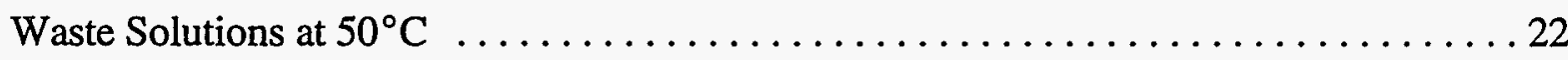

9 Extraction of Iodide and Iodate from SY- 101 at 25 and $50^{\circ} \mathrm{C}$ by PEGs $\ldots \ldots \ldots \ldots 23$

10 Pertechnetate Extraction from Waste Simulants by Immobilized

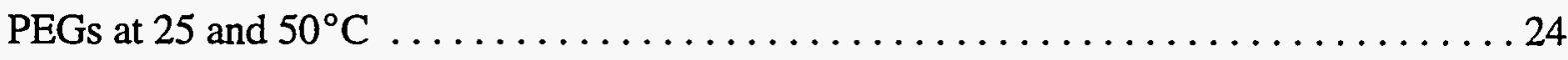

11 Effect of IDA on Pertechnetate Extraction using Tenta Gel Resins at $25^{\circ} \mathrm{C} \ldots \ldots \ldots 25$ 


\section{TABLES (Cont.)}

12 Comparison of Pertechnetate Extraction from SY-101 Simulant by

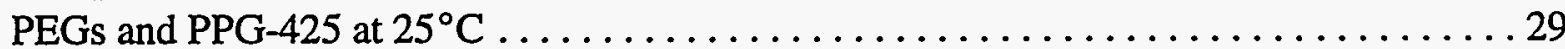

13 Extraction of Pertechnetate from the SY-101 Simulant by PPGs at $25^{\circ} \mathrm{C} \ldots \ldots \ldots \ldots 29$

14 Partition Coefficient for Electrolytes with Various PPGs at $25^{\circ} \mathrm{C} \ldots \ldots \ldots \ldots \ldots 30$

15 Partition Coefficient for Electrolytes with Various PPGs at $50^{\circ} \mathrm{C} \ldots \ldots \ldots \ldots \ldots$

16 Separation of Pertechnetate from Other Electrolytes in

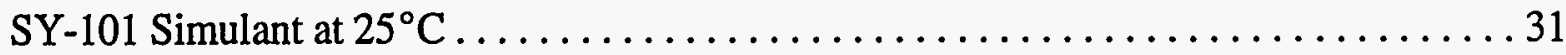

17 Partitioning of Pertechnetate between PPG-725 and Simulated

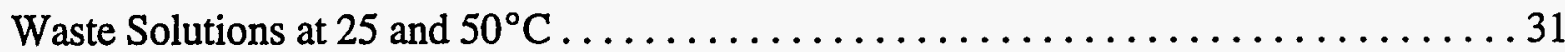

18 Partitioning of Pertechnetate between PPG-725 and $1 \underline{\mathrm{M}} \mathrm{NaNO}_{3}$ at $25^{\circ} \mathrm{C} \ldots \ldots \ldots . \ldots 32$

19 Partitioning of Pertechnetate between PPG-725 and Aqueous Sodium

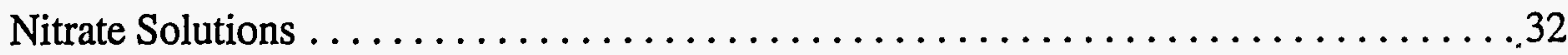

20 Back Extraction of Pertechnetate from PPG-725 Phases Using

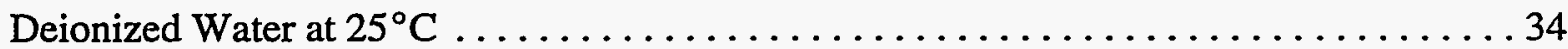

21 Partitioning of Iodide between PPG-725 and Waste Simulant

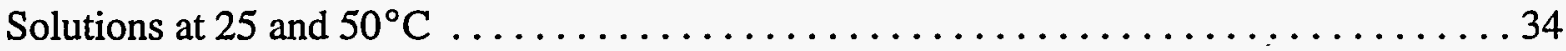

A-1 Composition of Hanford Tank SY-101 Supernatant $\ldots \ldots \ldots \ldots \ldots \ldots \ldots \ldots \ldots \ldots$

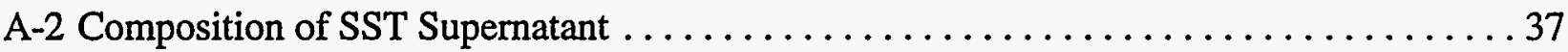

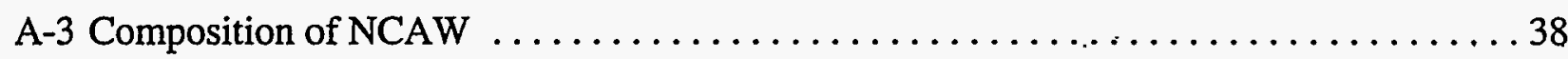

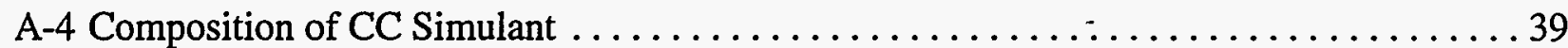

A-5 Phase Separation Times and Dispersion Numbers for the PEG-2000/Waste Simulant Systems at 25 and $50^{\circ} \mathrm{C}$ 


\section{TABLES (Cont.)}

B-1 Identification of VOCs Generated in Aqueous PEG Solutions after a $6 \mathrm{Mrad}$ Exposure to $\gamma$ Radiation at Room Temperature ............... 47

B-2 Identification of VOCs Generated by $\gamma$ Irradiation of PEG-1500 Solutions at Doses of 0 and $20 \mathrm{Mrad}$

\section{FIGURES}

1 Partitioning of Pertechnetate between PEG-4000 and $\mathrm{K}_{2} \mathrm{CO}_{3} \ldots \ldots \ldots \ldots \ldots$

2 Phase Diagrams for the PEG/Na $/ \mathrm{CO}_{3}$ System as a Function of PEG

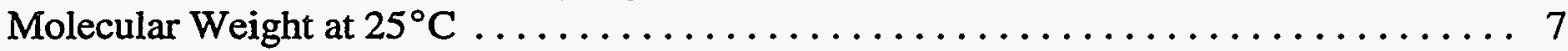

3 Phase Diagrams for PEG-2000/Waste Simulant Systems $\ldots \ldots \ldots \ldots \ldots \ldots \ldots$

4 Effect of $\mathrm{NaNO}_{3}$ Concentration on the Extraction of Pertechnetate by PEG-2000 from $\mathrm{NaOH} / \mathrm{NaNO}_{3}$ Mixtures at $25^{\circ} \mathrm{C} \ldots \ldots \ldots \ldots \ldots \ldots \ldots \ldots \ldots \ldots \ldots$

5 Effect of Mixing Time on the Extraction of Pertechnetate from Hanford

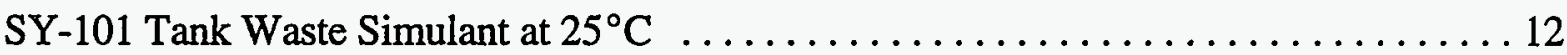

6 Effect of PEG-2000 Concentration on the Partitioning of Pertechnetate

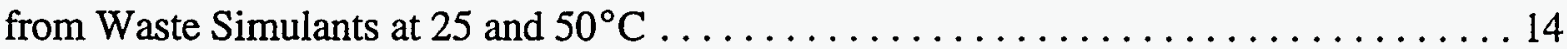

7 Partitioning of Phosphate Between PEG-2000 and the Waste Simulants

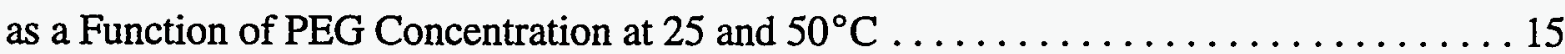

8 Partitioning of Sulfate Between PEG-2000 and Waste Simulants as a Function of PEG Concentration at 25 and $50^{\circ} \mathrm{C} \ldots \ldots \ldots \ldots \ldots \ldots \ldots \ldots \ldots \ldots$

9 Partitioning of Carbonate Between PEG-2000 and Waste Simulants

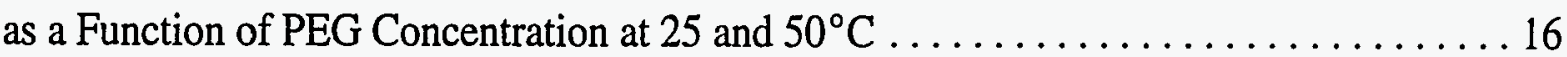

10 Partitioning of Sodium Between PEG-2000 and Waste Simulants

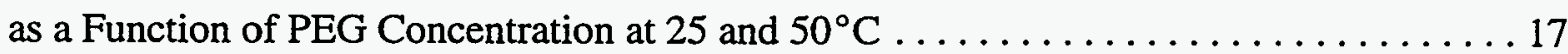




\section{FIGURES (Cont.)}

11 Partitioning of ${ }^{14} \mathrm{C}$-Labeled PEG-4000 as a Function of PEG Concentration

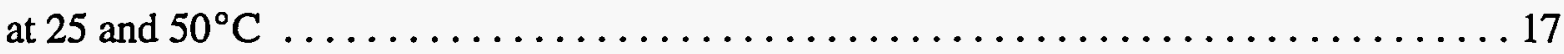

12 Partitioning of Pertechnetate onto TS-OH and TS-Br Resins as a Function of

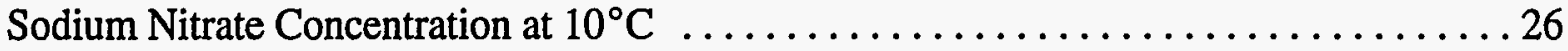

13 Partitioning of Pertechnetate onto TS-OH and TS-Br Resins from Deionized

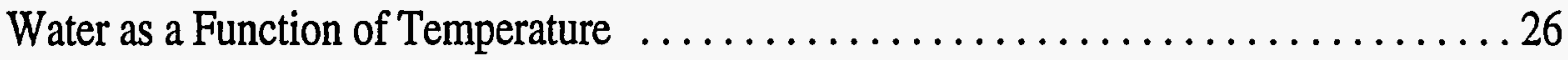




\section{ACRONYMS}

$\mathrm{ABE} \quad$ Aqueous biphasic extraction

ANL Argonne National Laboratory

CC Complexant concentrate

EDTA Ethylenediaminetetraacetic acid

HEDTA N-(2-hydroxyethyl)ethylenediaminetriacetic acid

IDA Iminodiacetic acid

NCAW Neutralized current acid waste

NTA Nitriotriacetic acid

PEG Polyethylene glycol

PPG Polypropylene glycol

SST Single-shell tank

VOC Volatile organic compound 


\title{
EXTRACTION OF LONG-LIVED RADIONUCLIDES \\ FROM CAUSTIC HANFORD TANK WASTE SUPERNATANTS
}

by

D.J. Chaiko, C.J. Mertz, Y. Vojta,

J.L. Henriksen, R. Neff, and M. Takeuchi

Chemical Technology Division

\begin{abstract}
A series of polymer-based extraction systems, based on the use of polyethylene glycols (PEGs) or polypropylene glycols (PPGs), was demonstrated to be capable of selective extraction and recovery of long-lived radionuclides, such as ${ }^{99} \mathrm{Tc}$ and ${ }^{129} \mathrm{I}$, from Hanford SY-101 tank waste, neutralized current acid waste, and single-shell tank waste simulants. During the extraction process, anionic species like $\mathrm{TcO}_{4}{ }^{-}$and $\mathrm{I}^{-}$are selectively transferred to the less dense PEGrich aqueous phase. The partition coefficients for a wide range of inorganic cations and anions, such as sodium, potassium, aluminum, nitrate, nitrite, and carbonate, are all less than one. The partition coefficients for pertechnetate ranged from 12 to 50, depending on the choice of waste simulant and temperature. The partition coefficient for iodide was about 5 , while that of iodate was about 0.25 . Irradiation of the PEG phase with gamma-ray doses up to $20 \mathrm{Mrad}$ had no detectable effect on the partition coefficients. The most selective extraction systems examined were those based on PPGs, which exhibited separation factors in excess of 3000 between $\mathrm{TcO}_{4}{ }^{-}$and $\mathrm{NO}_{3}{ }^{-} \mathrm{NO}_{2}{ }^{-}$. An advantage of the PPG-based system is minimization of secondary waste production. These studies also highlighted the need for exercising great care in extrapolating the partitioning behavior with tank waste simulants to actual tank waste.
\end{abstract}




\section{SUMMARY AND CONCLUSIONS}

Near-surface disposal of single-shell tank supernatants, after conversion to grout, would require that long-lived isotopes such as ${ }^{129} \mathrm{I},{ }^{99} \mathrm{Tc}$, and ${ }^{79} \mathrm{Se}$ be removed. Ion-exchange technology for removal of cesium from alkaline solutions is well developed, whereas little or no technology is available for recovery of iodine, technetium, or selenium from alkaline solutions at high ionic strength.

In an effort to address these needs, we evaluated the applicability of aqueous biphasic extraction $(A B E)$ systems to the pretreatment of supernatant solutions from underground storage tanks. The $\mathrm{ABE}$ systems permit the selective extraction and recovery of dissolved inorganic ions from electrolyte solutions having high ionic strength. Biphasic aqueous systems can be generated by the addition of polyethylene glycols (PEGs) or polypropylene glycols (PPGs) to high-ionicstrength electrolyte solutions.

The primary objective of this work was to demonstrate the ability to remove long-lived radionuclides (such as ${ }^{99} \mathrm{Tc},{ }^{129} \mathrm{I}$, and ${ }^{79} \mathrm{Se}$ ) from alkaline solutions. The selective removal of these species by aqueous biphasic separation could be coupled with ion-exchange processes to remove cationic species, such as ${ }^{137} \mathrm{Cs}$ and transuranics, from alkaline solution. This would permit nearsurface disposal of the bulk of the alkaline supernatants and dissolved salt cake from underground storage tanks. The extractions could be carried out without $\mathrm{pH}$ adjustment, and the only reagent added to the waste stream would be a minimum amount of water to ensure dissolution of the salt cake.

Aqueous biphase formation was demonstrated at 25 and $50^{\circ} \mathrm{C}$ with Hanford SY-101 tank waste, neutralized current acid waste, and single-shell tank waste simulants. Partitioning studies were conducted by using PEGs having average molecular weights of 1500,2000 , and 3400 . The partition coefficients for pertechnetate ranged from 12 to 50, depending on the choice of waste simulant and temperature. The partition coefficients for iodide were about 5 , while those for iodate were about 0.25. Irradiation of the PEG phase with $\gamma$-ray doses up to $20 \mathrm{Mrad}$ had no detectable effect on partition coefficients. This dose approximates the yearly dose that would be received by the solvent in processing tank waste from SY-101 without prior removal of ${ }^{137} \mathrm{Cs}$ and ${ }^{90} \mathrm{Sr}$.

A series of commercially available resins containing immobilized PEGs were also examined for their ability to extract pertechnetate from alkaline solutions and tank waste simulants. These systems are of interest because they combine certain extraction properties of the liquid/liquid PEG systems with the elimination of polymer losses due to dissolution into the process stream. In tests on macroporous resins, with a 70-80 wt\% PEG content, we found that the extraction behavior of the immobilized PEGs differed markedly from that of the liquid/liquid systems. While partition coefficients for pertechnetate as high as 100-300 could be obtained from the waste simulants, the 
extraction behavior was highly dependent on temperature and solution composition. One of the resins, Tenta $\mathrm{Gel} \mathrm{SBr}$ performed best (i.e., partition coefficient $>3000$ ) in the extraction of pertechnetate from low-ionic-strength aqueous solutions at reduced temperature (i.e., $15-20^{\circ} \mathrm{C}$ ).

We also focused our efforts on improving extraction selectivity and enhancing the backextraction efficiency of the $\mathrm{ABE}$ systems. In working toward this goal, we found that biphasic extraction systems based on polypropylene glycols offer certain advantages over PEG-based systems. For example, their lower solubility in water would reduce polymer losses due to dissolution into the aqueous process streams. Extraction of pertechnetate from simulated tank waste supernatants by PPGs was rapid, and extraction selectivities were significantly improved compared with those obtained with PEGs. Partition coefficients of pertechnetate ranged from 10 to 100 , whereas the partition coefficients of many tank waste constituents (e.g., $\mathrm{Al}^{3+}, \mathrm{PO}_{4}{ }^{3-}, \mathrm{SO}_{4}{ }^{2-}$, and $\mathrm{F}$ ) were below 0.001 . There was an inverse relationship between extraction of pertechnetate and PPG molecular weight. This extraction behavior is related to the degree of hydration of the polymer. Interestingly, extraction selectivity for pertechnetate over $\mathrm{Na}^{+} / \mathrm{NO}_{3}{ }^{-} / \mathrm{NO}_{2}{ }^{-}$increased dramatically in going from PPG-425 to PPG-725. The separation of $\mathrm{TcO}_{4}{ }^{-}$from $\mathrm{NO}_{3}{ }^{-}$has traditionally been difficult. With PPG-725, we obtained single-stage separation factors in excess of 3,000 between $\mathrm{TcO}_{4}{ }^{-}$and $\mathrm{Na}^{+} / \mathrm{NO}_{3}^{-}$, while the extraction of $\mathrm{Al}^{3+}$ was below detection limits. Another advantage of the PPGbased systems is minimization of secondary waste production because deionized water can be used to strip pertechnetate from the loaded polymer phase. For example, PPG-725 could be used to extract technetium from tank supernatants with high ionic strength and then regenerated by stripping with deionized water.

Our studies also highlighted the need for exercising great care in extrapolating the partitioning behavior for tank waste simulants to actual tank waste. Subtle changes in the preparation of the simulants led to significant changes in technetium partitioning behavior. For example, the choice between the use of paper or glass-frit filters in removing residual particulates from freshly prepared simulants led to changes in the free energy of extraction $\left(\Delta \mathrm{G}_{\mathrm{ext}}\right)$ and significant differences in the temperature dependency of $\Delta \mathrm{G}_{\text {ext }}$. The complex speciation of the tank wastes and their simulants will undoubtedly impact the outcome and interpretation of tank waste studies. At present, the tank waste recipes offer no guidance on controlling either the composition or physical characteristics of colloidal species. In the absence of actual waste studies, waste simulant recipes that reflect not only the elemental composition but also the colloidal composition of the tank wastes are needed. 


\section{INTRODUCTION}

The purpose of this project was to examine the use of aqueous biphasic extraction (ABE) systems for the pretreatment of supernatant solutions from underground storage tanks. The primary objective of pretreatment is to selectively remove long-lived radionuclides, such as ${ }^{129} \mathrm{I},{ }^{75} \mathrm{Si}$, and ${ }^{99} \mathrm{Tc}$, from caustic solutions containing high concentrations of sodium, potassium, nitrate, nitrite, and carbonate.

We used alkyl polyether alcohols, such as polyethylene glycols (PEGs) and polypropylene glycols (PPGs) to form aqueous biphase systems. Due to a combination of hydration properties and cloud point phenomena, PEG can form biphasic systems in the presence of high-ionic-strength salt solutions. These biphasic solvent extraction systems contain water as the diluent in both phases; each phase can contain as much as 70-80 wt\% water [Albertsson]. Because of the high ionic strengths of the supernatant liquids in the Hanford underground storage tanks, aqueous biphase systems can be generated by simply contacting aqueous PEG solutions with the waste solution.

In the $\mathrm{ABE}$ systems that we studied, species like $\mathrm{I}^{-}$and $\mathrm{TcO}_{4}{ }^{-}$are transferred from the more dense salt phase to the less dense polymer-rich phase, with partition coefficients greater than one [Rogers]. By contrast, the partition coefficients for a wide range of inorganic cations and anions in $\mathrm{PEG} /$ salt biphase systems, are generally less than one [Albertsson]. Thus, $\mathrm{ABE}$ systems offer the potential for selective extraction of long-lived radionuclides from high-level liquid waste.

During the course of this study, we examined the ability of PEGs to selectively extract iodide, iodate, and pertechnetate from simulated Hanford tank supernatants. Three tank waste simulants (nonradioactive) were used: NCAW (neutralized current acid waste), SST (single-shell tank) supernatant, and Hanford SY-101 supernatant. The major constituents of all these waste simulants are nitrate and nitrite salts. While these salts do not promote aqueous biphase formation with PEGs, the concentration of hydroxide, sulfate, carbonate, and phosphate in the three waste simulants is sufficient to support aqueous biphase formation with PEGs that have molecular weights equal to or greater than 1500 .

During the course of this work, our attempts to improve extraction selectivity and enhance efficiency of back extraction, led to the investigation of solid-state aqueous biphase systems and water-immiscible PPGs. Our goal was to develop a highly selective extraction system, in an engineered form that is capable of scale-up and that produces minimal amounts of secondary wastes.

This report summarizes the extraction capabilities of various polymer systems that are based on the use of PEGs and PPGs. Work was performed both at Argonne National Laboratory (ANL) and at Northern Illinois University (NIU). 


\section{BACKGROUND}

High-level radioactive wastes generated during the years of fuel-reprocessing activities at Hanford, were placed in underground tanks for storage. To prevent tank corrosion, the wastes were made alkaline, thereby causing the bulk of the transuranic elements and fission products to precipitate and form a sludge. Also contained in the tanks are an aqueous supernatant and a lowdensity salt cake. The supernatant consists primarily of the soluble salts of nitrate, nitrite, phosphate, and carbonate but also contains lesser amounts of fluorides, sulfates, and chlorides [Kupfer].

The principal sources of radiation in the water-soluble fraction of the tank wastes are ${ }^{137} \mathrm{Cs}$ and ${ }^{90} \mathrm{Sr}$ [Straalsund]. One treatment option for the alkaline supernatant and salt cake involves the extraction of $\mathrm{Cs}$, Sr, and long-lived radionuclides such as ${ }^{99} \mathrm{Tc}$, prior to disposal in a vitrified waste form as high-level waste (HLW). Long-term risks to the environment could be minimized by storage of HLW, together with long-lived radionuclides, in a deep geologic repository. The bulk of the remaining water-soluble fraction would be a low-level waste (LLW), which could be converted to a suitable waste form for near-surface storage. The various waste treatment strategies that have been proposed have focused on radionuclide removal from the low-level waste stream as a means of meeting the U.S. Department of Energy's ALARA (as low as reasonably achievable) policy. Technetium removal from the LLW may also be required in order to meet LLW vitrification performance goals.

The total inventory of technetium and iodine contained in Hanford tank waste is estimated to be $5 \times 10^{5} \mathrm{~g}$ each [DOE]. The concentration of technetium in a typical process feed solution is expected to be approximately $15 \mathrm{mM}$. This assumes that the salt cake and supernatant are dissolved in sufficient water to produce a sodium concentration of $5 \underline{\mathrm{M}}$ [DOE].

A recently published review identifies several solvent extraction and ion-exchange processes that have been examined for technetium removal from acidic and basic radioactive wastes [Kolarik]. The best commercially available technologies for removing iodine and technetium from basic solutions involve (a) volatilization with off-gas scrubbing and (b) ion exchange [Swanson]. There are uncertainties regarding the efficiency of iodine removal. Also, the use of a strong-base anion exchanger for the recovery of technetium would require relatively large volumes of wash and strip solutions to elute the technetium from the ion exchanger [Swanson].

A number of solvent systems for the extraction of $\mathrm{TcO}_{4}{ }^{-}$from aqueous solutions have been investigated [Anders]. In a systematic study of $\mathrm{TcO}_{4}{ }^{-}$extraction into water-immiscible organics, Boyd and Larson [Boyd] showed that the best extraction occurred in organic solvents possessing an appreciable dielectric constant and containing a basic oxygen or nitrogen atom. 
The use of cyclohexanone in solvent extraction processes for $\mathrm{TcO}_{4}{ }^{-}$removal from alkaline waste solutions was evaluated by Schultz in 1980 [Schultz]. The approach involved the countercurrent extraction of technetium by cyclohexanone, followed by water stripping. The procedure was complicated by emulsification of the solvent with water during stripping [Schulz].

The water immiscible polyethers, dibutoxytetraethylene glycol and dibutoxydiethylene glycol, showed a modest capability to extract $\mathrm{TcO}_{4}^{-}$from caustic solutions; the higher molecular weight ethylene glycol moiety, tetraethylene glycol, demonstrated a higher extraction affinity for $\mathrm{TCO}_{4}^{-}$[Boyd].

Aqueous biphase systems that are generated by salting out polyethylene glycols are capable of quantitatively extracting technetium as $\mathrm{TcO}_{4}{ }^{-}$into the PEG-rich upper phase without the addition of an extractant. Partition coefficients in excess of 1500 are observed for $\mathrm{TcO}_{4}{ }^{-}$in carbonate/PEG biphase systems (see Figure 1). The partition coefficients for $\mathrm{CO}_{3}{ }^{2-}$ and PEG-4000 are approximately 0.14 and 980 , respectively [Chaiko-1993 B]. Another anionic species, $\mathrm{I}^{-}$[Zarova], also partitions preferentially into the upper PEG phase in a PEG/salt biphase system without an added extractant. By contrast, the partition coefficients for a wide range of inorganic cations such as $\mathrm{Na}^{+}, \mathrm{K}^{+}, \mathrm{Fe}^{3+}, \mathrm{Al}^{3+}, \mathrm{Zr}^{4+}$, the lanthanides, and the actinides are all less than one in $\mathrm{PEG} / \mathrm{salt}$ biphase systems. Thus, the potential exists for the use of PEG-based systems for selectively separating certain anionic species from complex salt solutions.

Although association complexes between salts, such as $\mathrm{KI}, \mathrm{KI}_{3}$, and $\mathrm{HgCl}_{2}$, and polyethylene oxide have been demonstrated, they occur only in anhydrous solvents like methanol [Lundberg, Blumberg, Iwamoto]. In light of the work of Boyd and Larson [Boyd], it is not surprising that PEG-based biphase systems are capable of extracting $\mathrm{TcO}_{4}^{-}$.

The phase diagrams for PEGs of various molecular weight in $\mathrm{PEG} / \mathrm{Na}_{2} \mathrm{CO}_{3}$ systems at $25^{\circ} \mathrm{C}$ are shown in Figure 2. Comparison of the partition data in Figure 1 with the phase diagrams in Figure 2 shows that the partition coefficient of $\mathrm{TcO}_{4}{ }^{-}$decreases rapidly as the biphase system approaches the phase boundary.

Salts with multicharged anions, such as sulfate, carbonate, and phosphate, are effective at promoting biphase formation with PEGs [Ananthapadmanabhan]. Singly charged anions, such as nitrate, chloride, bromide, iodide, and iodate, do not promote biphase formation with PEGs at temperatures under $100^{\circ} \mathrm{C}$ [Ananthapadmanabhan]. Interestingly, hydroxide and fluoride are capable of biphase formation when present at high concentration.

The relationship between charge and biphase-forming tendency does not hold for cations. The more effective cations are those with a single charge, such as $\mathrm{Na}^{+}$and $\mathrm{K}^{+}$, whereas multivalent cations, such as $\mathrm{Al}^{3+}$ tend to reduce the salting-out effect. This reversal in trend is 


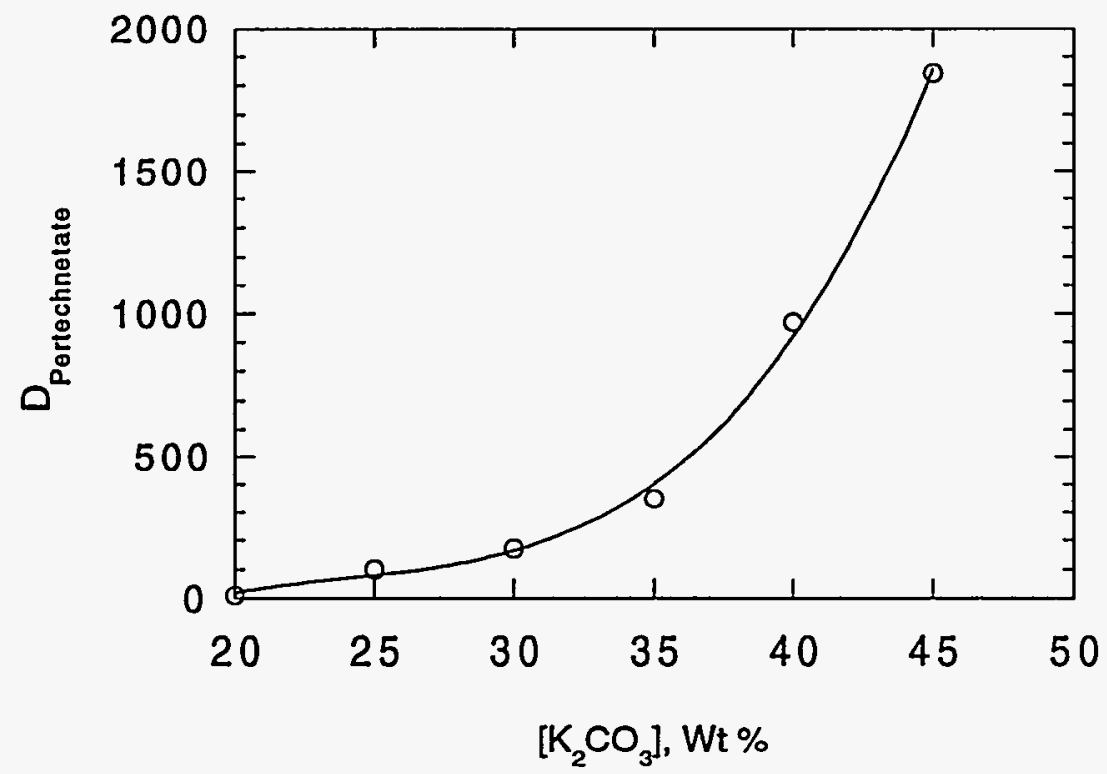

FIGURE 1 Partitioning of Pertechnetate between PEG-4000 and $\mathrm{K}_{2} \mathrm{CO}_{3}$

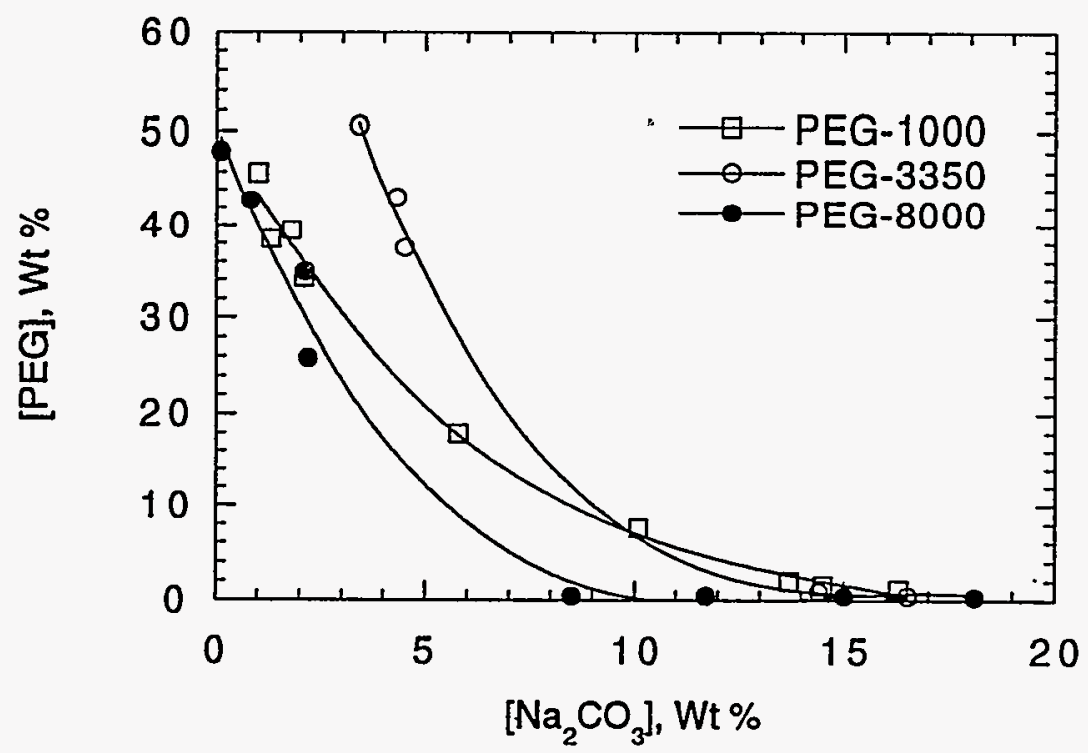

FIGURE 2 Phase Diagrams for the PEG/Na $\mathrm{CO}_{3}$ System as a Function of PEG Molecular Weight at $25^{\circ} \mathrm{C}$. Data from [Snyder]. 
believed to be due to a tendency toward direct interaction between multivalent cations and the ethylene oxide units of PEG [Ananthapadmanabhan].

Temperature also has a significant influence on biphase formation in PEG/salt systems. For example, increasing the temperature of a $\mathrm{PEG} / \mathrm{Na}_{2} \mathrm{CO}_{3}$ system allows biphase formation to occur at lower concentrations of PEG and salt [Chaiko-1993B]. This phase separation behavior has been directly linked to the clouding phenomenon that occurs in PEG solutions upon heating [Ananthapadmanabhan]. Conversely, increasing the salt concentration reduces the clouding temperature of PEG solutions [Ananthapadmanabhan]. Consequently, self-heating of HLW solutions would be expected to aid in biphase formation.

Biphase formation in salt solutions with polymers like $\mathrm{PEG}$, is a complex phenomenon that cannot be predicted solely on the basis of the ionic strength or water activity of the salt solution. Whether or not biphase formation will be possible with actual tank waste will depend upon the concentrations of hydroxide, phosphate, carbonate, and fluoride in the waste solution. Dilution of the waste with water to facilitate processing will have to be done carefully, since this action could potentially prevent biphase formation with the PEGs. On the other hand, low-molecular-weight polypropylene glycols (PPGs) are capable of forming aqueous biphase systems with dilute solutions containing sodium nitrate and nitrite. Both polymers were investigated in this study to determine their potential for selective extraction of technetium and iodine from caustic tank supernatants. 


\section{AQUEOUS BIPHASE FORMATION WITH POLYETHYLENE GLYCOLS AND TANK WASTE SIMULANTS}

The physical properties of ABE systems depend on the type and concentration of the PEG and salt (waste) phases, the temperature, and the nature and concentrations of other matrix ions present in solution.

The composition and method of preparation of the three waste simulants that we studied are described in Appendix A. It should be noted that the preparation of all three simulants produced some precipitate. Preparation of SY-101 produced the largest amount of precipitate, while precipitation from NCAW and SST was slight. The phase diagrams for PEG-2000 with SY-101, NCAW, and SST are shown in Figure 3. The phase diagrams for SST and NCAW are nearly identical, while the SY-101 binodals were shifted to lower salt concentrations. In all cases, the binodals shifted to lower salt concentrations as the temperature of the system was increased.

The phase separation times $(t)$ and dispersion numbers $\left(\mathrm{N}_{D_{i}}\right)$ for the three systems at 25 and $50^{\circ} \mathrm{C}$ are described in Appendix A, Section 3. The $\mathrm{N}_{\mathrm{Di}}$ values increased with increasing temperature (i.e., phase separation times decreased), but at a given temperature $\mathrm{N}_{\mathrm{Di}}$ values for the $\mathrm{NCAW}$ and SST systems were similar, and higher than the $\mathrm{N}_{\mathrm{Di}}$ value for SY-101. The phase separation rates are a function of interfacial tension, the density difference between the two liquid phases, and the liquidphase viscosities. Thus, the hydrodynamic properties of the aqueous biphase system for an actual waste will depend on operating temperature, choice of polymer and concentration, and the concentration of water in the waste feed. Given the $\mathrm{N}_{\mathrm{Di}}$ values obtained with the waste simulants, the extraction systems should be compatible with conventional contractor equipment. 


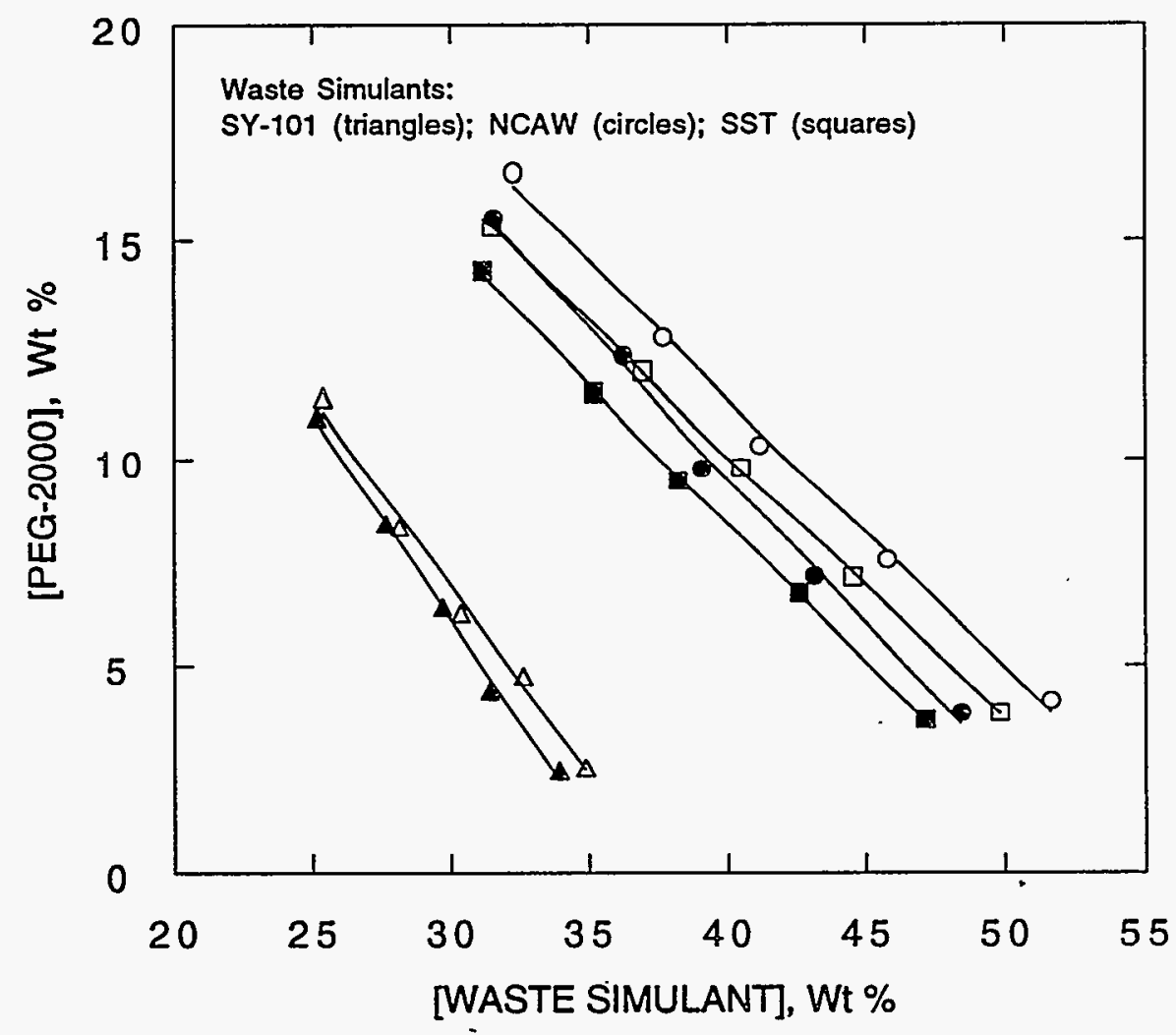

FIGURE 3 Phase Diagrams for PEG-2000/Waste Simulant Systems. The Open Symbols Represent $25^{\circ} \mathrm{C}$ Data and the Solid Symbols Represent $50^{\circ} \mathrm{C}$ Data. 


\section{POLYETHYLENE GLYCOL EXTRACTION SYSTEMS}

The partitioning behavior of technetium, iodine, and other components of the aqueous biphase extraction system was examined. The partition coefficient (or distribution ratio), $D_{x}$, was used as a measure of the extraction of a component, $x$, from the salt-rich phase into the PEG-rich phase. Details of the measurement of partition coefficients are provided in Appendix A, Section 4 Partitioning behavior was studied as a function of PEG molecular weight, waste stream composition (including the presence of uranium), and temperature. The effect on partitioning of using slightly different techniques in preparing the waste simulants was also examined. Given the complex nature of the tank wastes, the physicochemical properties (e.g., colloid formation) of the simulants are likely to depend on the method of preparation.

\subsection{EXTRACTION OF PERTECHNETATE}

Although nitrate and nitrite do not promote aqueous biphase formation with PEGs, the concentration of hydroxide in the waste simulants was evidently high enough to support biphase formation with PEGs having molecular weights from 1500 to 3400 (see Figure 3). The partitioning data in Figure 4 show that the presence of high concentrations of non-biphase-forming salts, such as sodium nitrate, depressed the extraction of pertechnetate by PEG. However, even at high nitrate concentrations (i.e., $1-4 \underline{M}$ ) the $D$ values were greater than 40 . Thus, the $P E G$ systems exhibit good extraction selectivity for $\mathrm{TcO}_{4}^{-}$over $\mathrm{NO}_{3}^{-}$.

Measurement of $D$ values as a function of mixing time indicated that extraction of pertechnetate from the salt-rich phase into the PEG phase is rapid, as equilibrium was obtained with mixing times as short as $30 \mathrm{~s}$ (Figure 5). It should be noted that, for the data in Figure 5 , the ${ }^{99} \mathrm{Tc}$ tracer was added to the salt phase before contacting with the PEG-rich phase. Thus, by definition, the $D$ value at $t=0$ was zero. Identical $D$ values were obtained regardless of whether the pertechnetate was added into the PEG phase or the salt phase, which also supports a rapid approach to equilibrium.

The extraction of $\mathrm{TcO}_{4}^{-}$from the waste simulants was examined as a function of temperature and PEG molecular weight. The partitioning behavior of $\mathrm{TcO}_{4}^{-}$was only slightly affected by temperature for both PEG-1500 and PEG-3400. However, regardless of temperature, the $D$ values were about five times higher for SY-101 than they were for the other waste simulants (see Table 1). The extraction data in Table 1 also indicate that increasing the molecular weight of the polymer increased the D values. This effect was most pronounced for the PEG/SY-101 systems. 


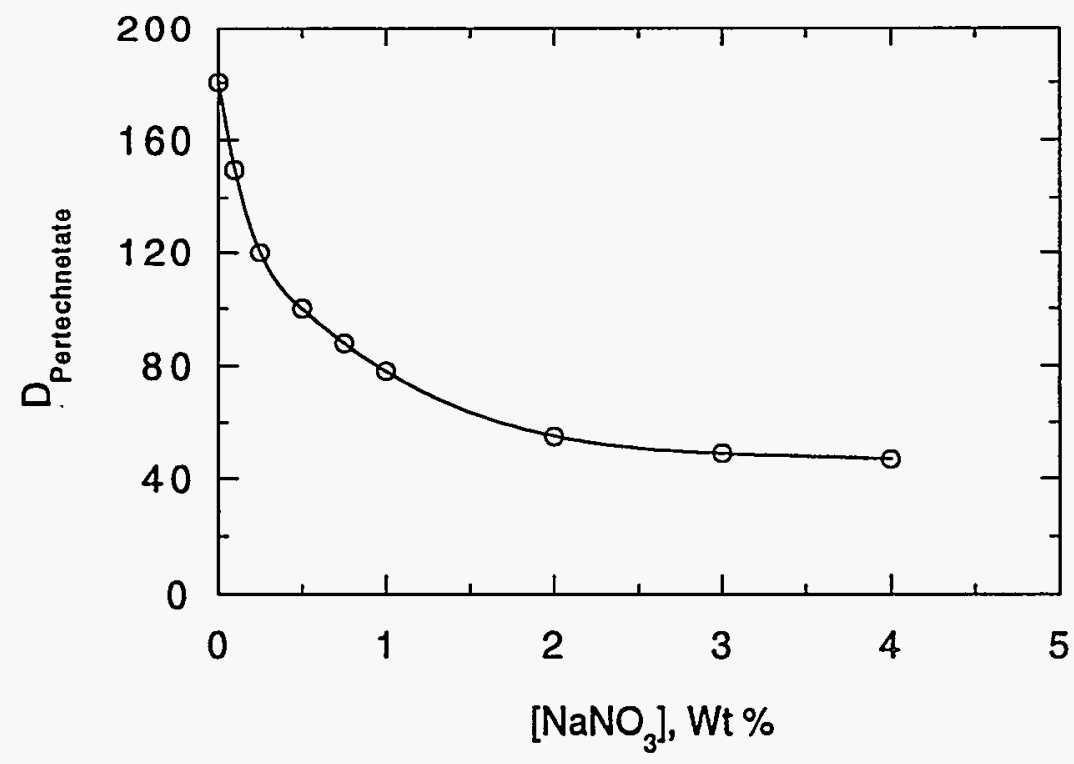

FIGURE 4 Effect of $\mathrm{NaNO}_{3}$ Concentration on the Extraction of Pertechnetate by PEG-2000 from $\mathrm{NaOH} / \mathrm{NaNO}_{3}$ Mixtures at $25^{\circ} \mathrm{C}$

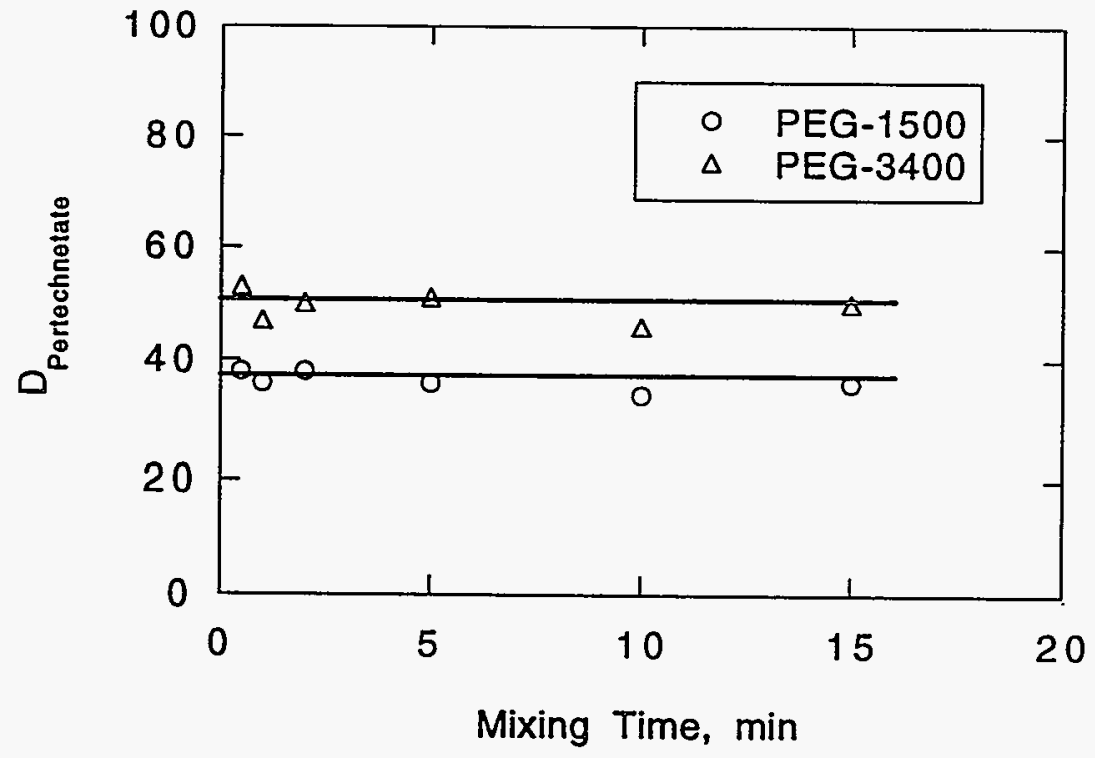

FIGURE 5 Effect of Mixing Time on the Extraction of Pertechnetate from Hanford SY-101 Tank Waste Simulant at $25^{\circ} \mathrm{C}$ 
Distribution ratios for $\mathrm{TcO}_{4}^{-}$in PEG2000/waste simulant systems at 25 and $50^{\circ} \mathrm{C}$ are shown as a function of PEG concentration in Figure 6. The extraction of $\mathrm{TcO}_{4}^{-}$was greatest for SY-101 and reached values as high as 200 with $60 \mathrm{wt} \%$ PEG-2000. The SST results were consistently (but only slightly) lower than those for NCAW, and maximum D values were 32 (NCAW) and 24 (SST) with $60 \mathrm{wt} \%$ PEG-2000. At lower PEG-2000 concentrations, the distribution ratios for SY-101 and NCAW at $50^{\circ} \mathrm{C}$ were higher than those at $25^{\circ} \mathrm{C}$. At higher concentrations of PEG-2000, the distribution ratios at $50^{\circ} \mathrm{C}$ increased smoothly, while the $25^{\circ} \mathrm{C}$ distribution increased more sharply. The end result was higher $D$ values with $60 \mathrm{wt} \%$ PEG-2000 for SY-101 and NCAW at $25^{\circ} \mathrm{C}$ compared with those at $50^{\circ} \mathrm{C}$.
TABLE 1 Extraction of Pertechnetate from Waste Simulants by PEG-1500 and PEG-3400 at 25 and $50^{\circ} \mathrm{C}$

\begin{tabular}{lrr}
\hline & \multicolumn{2}{c}{$\mathrm{D}$ Value, $\mathrm{TcO}_{4}^{-}$} \\
\cline { 2 - 3 } \multicolumn{1}{c}{ Biphase System } & $25^{\circ} \mathrm{C}$ & $50^{\circ} \mathrm{C}$ \\
\hline PEG-1500/SY-101 & 40 & 42 \\
PEG-1500/SST & 7 & 9 \\
PEG-1500/NCAW & 8 & 10 \\
& & \\
PEG-3400/SY-101 & 50 & 53 \\
PEG-3400/SST & 10 & 12 \\
PEG-3400/NCAW & 12 & 14 \\
\hline
\end{tabular}

Of significance to other waste treatment studies, we found that the partitioning behavior of pertechnetate was dependent on subtle differences in the method of waste simulant preparation (see Appendix A, Section 2 for procedures). This is illustrated by the data in Table 2, which describes pertechnetate extraction as a function of PEG molecular weight. The extraction data were obtained at a fixed biphase composition of $15 \mathrm{wt} \%$ PEG and $25 \mathrm{wt} \%$ SY-101 waste simulant.

Interestingly, the extraction of $\mathrm{TcO}_{4}^{-}$by PEG-1500, and PEG-3400 did not show a temperature dependency. However, the extraction of $\mathrm{TcO}_{4}{ }^{-}$by PEG- 2000 showed a definite temperature effect. These discrepancies in partitioning behavior underscore the difficulty of working with simulants of complex waste matrices that have been characterized only by chemical/elemental composition. We cannot overemphasize the need to validate the partition behavior of any extraction system with data generated from actual waste samples.

\subsection{PARTITIONING BEHAVIOR OF MAJOR TANK WASTE CONSTITUENTS}

Distribution ratio profiles for the major tank waste components were measured over a range of PEG-2000 concentrations from $20 \mathrm{wt} \%$ to $60 \mathrm{wt} \%$. It is important to consider the behavior over the entire range of concentrations when describing matrix ion partitioning in these systems. General observations that are made at one PEG concentration may not hold true over the entire range of concentrations. 


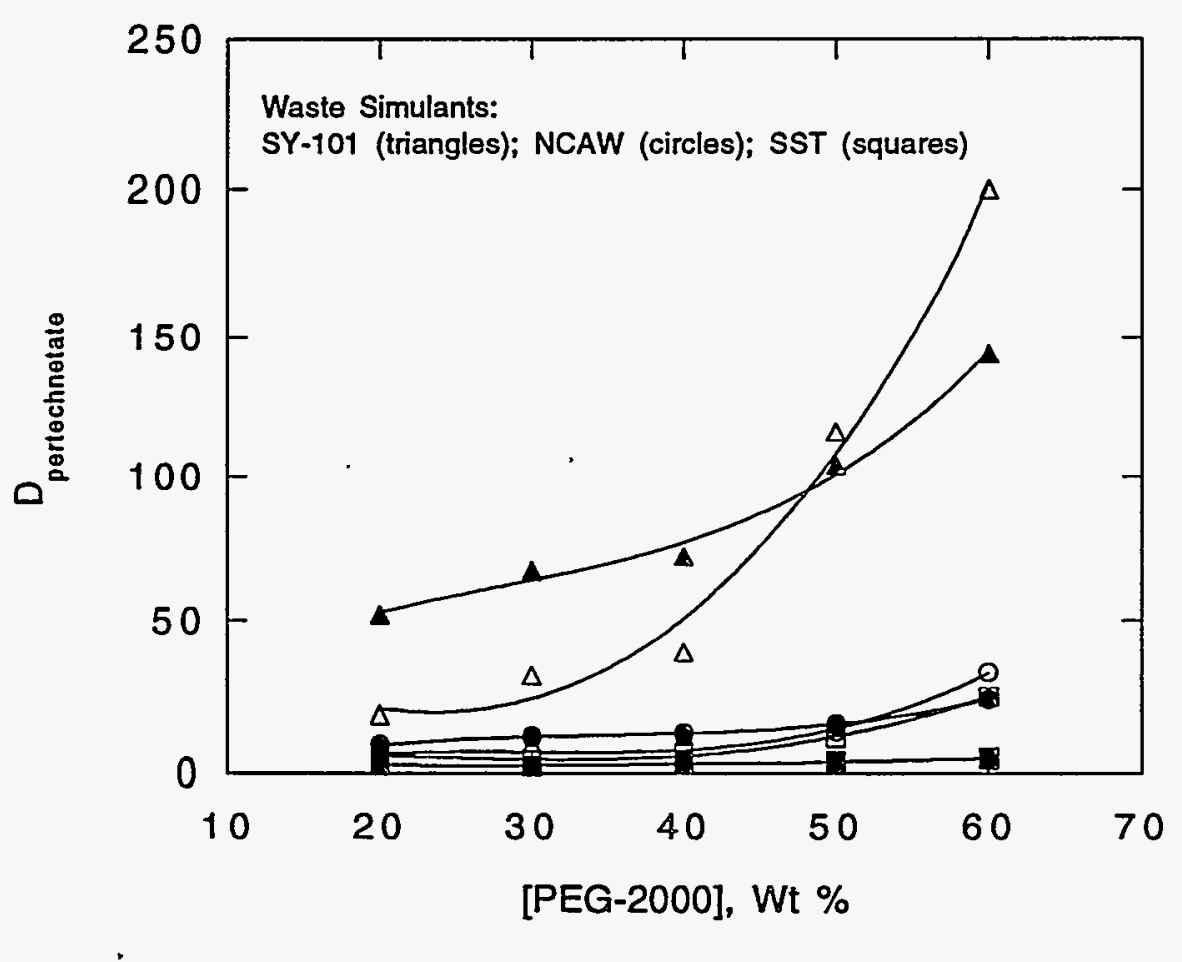

FIGURE 6 Effect of PEG-2000 Concentration on the Partitioning of Pertechnetate from Waste Simulants at 25 (open symbols) and $50^{\circ} \mathrm{C}$ (filled symbols)

We found similar phosphate distributions (Figure 7) in the SST and NCAW systems. At both 25 and $50^{\circ} \mathrm{C}$, there was a gradual decrease in $D$ values with increasing $P E G$ concentration. The partitioning behavior of phosphate in the SY-101 system was different; the partitioning of the phosphate ion increased slightly with increasing PEG concentration. This behavior was observed at both 25 and $50^{\circ} \mathrm{C}$.

The partitioning results for sulfate ion are presented in Figure 8. In general, the trends were similar to those observed for phosphate. At $25^{\circ} \mathrm{C}$, the NCAW and SST distribution profiles were very similar. There was a steady decrease in the $D$ values with increasing PEG concentration. For the SY-101 system there was a slight increase over the entire concentration range, although there was significant scatter in the data. The extraction profiles for the NCAW and SST waste simulants at $50^{\circ} \mathrm{C}$ revealed a smooth decrease in sulfate
TABLE 2 Extraction of Pertechnetate from SY-101 Waste Simulants as a Function of PEG Molecular Weight at 25 and $50^{\circ} \mathrm{C}$

\begin{tabular}{lll} 
& \multicolumn{2}{c}{$\mathrm{D}$ Value, $\mathrm{TcO}_{4}^{-}$} \\
\cline { 2 - 3 } $\begin{array}{c}\text { PEG Molecular } \\
\text { Weight }\end{array}$ & $25^{\circ} \mathrm{C}$ & $50^{\circ} \mathrm{C}$ \\
\hline $1500^{\mathrm{a}}$ & 40 & 42 \\
$2000^{\mathrm{b}}$ & 31 & 67 \\
$3400^{\mathrm{a}}$ & 50 & 53 \\
\hline
\end{tabular}

a Data collected at ANL

b Data collected at NIU 


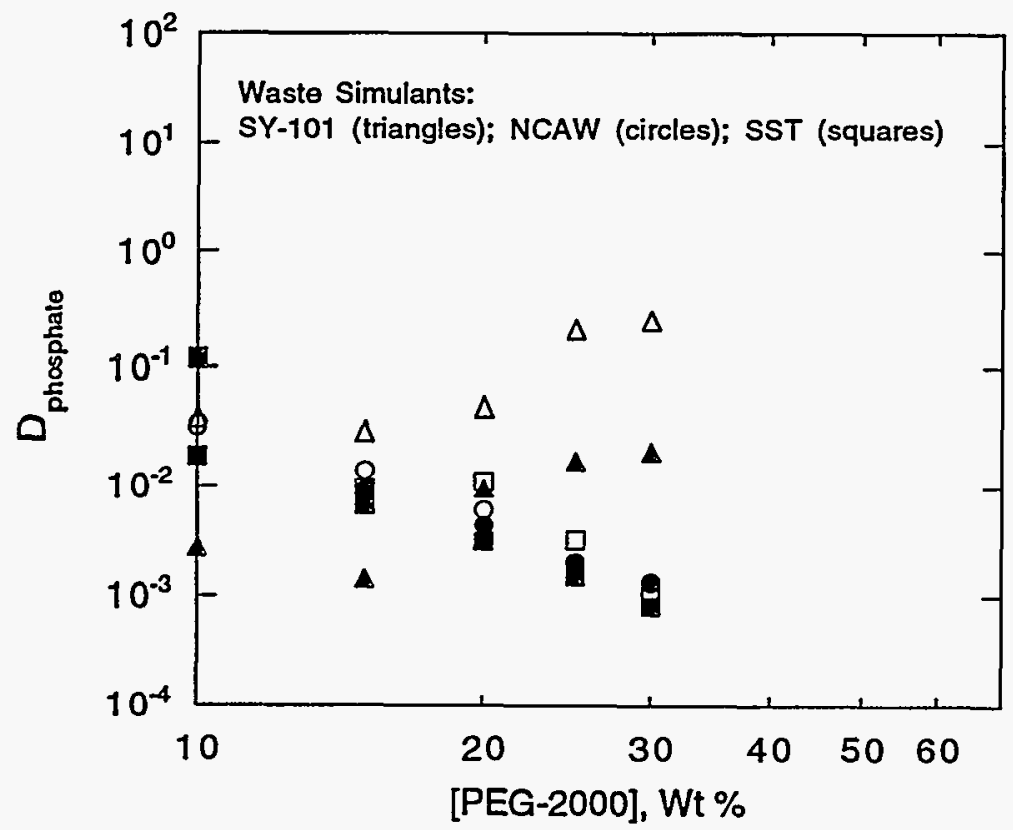

FIGURE 7 Partitioning of Phosphate Between PEG-2000 and the Waste Simulants as a Function of PEG Concentration at 25 (open symbols) and $50^{\circ} \mathrm{C}$ (filled symbols)

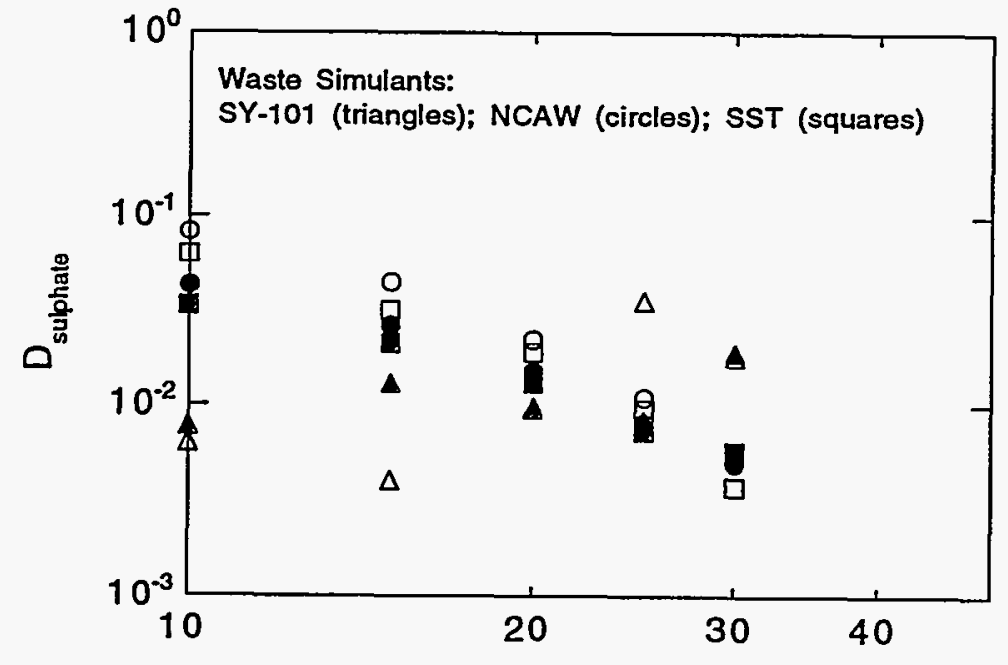

[PEG-2000], Wt \%

FIGURE 8 Partitioning of Sulfate Between PEG-2000 and Waste Simulants as a Function of PEG Concentration at 25 (open symbols) and $50^{\circ} \mathrm{C}$ (filled symbols) 
extraction with increasing PEG concentration, whereas the SY-101 system showed a slight increase in sulfate extraction at $60 \mathrm{wt} \%$ PEG-2000. At $50^{\circ} \mathrm{C}$ the partitioning was depressed slightly compared to that observed at $25^{\circ} \mathrm{C}$.

The partitioning behavior for carbonate is presented in Figure 9. The same basic trends observed previously hold for this anion also. The SY-101 system again showed the characteristic increase in distribution ratio at $50 \mathrm{wt} \%$ PEG-2000, whereas the NCAW and SST profiles were nearly identical and decreased gradually with increasing $\mathrm{PEG}$ concentration. At $50^{\circ} \mathrm{C}$ the distribution ratios for carbonate were slightly depressed, especially for the SY-101 system.

The extraction profiles for the sodium ion are presented in Figure 10. There was little difference in the partitioning behavior at 25 and $50^{\circ} \mathrm{C}$. In all cases there was a very slight decrease in sodium distribution ratios with increasing PEG concentration, but the variation across the entire concentration range was very small.

\subsection{PARTITIONING BEHAVIOR OF PEG}

The partitioning behavior of PEG in contact with the waste simulants is presented in Figure 11. Due to the unavailability of radiolabeled PEG-2000, we used radiolabeled PEG-4000 as a stand-in to estimate the $D_{P E G}$ values in the PEG-2000/waste simulant systems. The SY-101 system

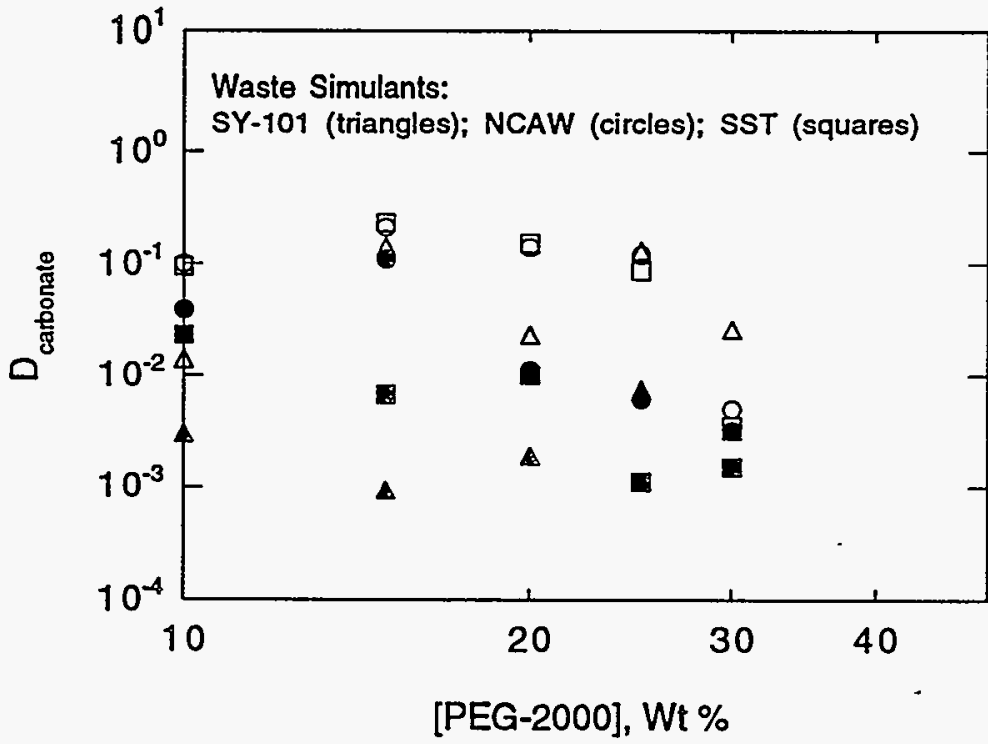

FIGURE 9 Partitioning of Carbonate Between PEG-2000 and Waste Simulants as a Function of PEG Concentration at 25 (open symbols) and $50^{\circ} \mathrm{C}$ (filled symbols) 


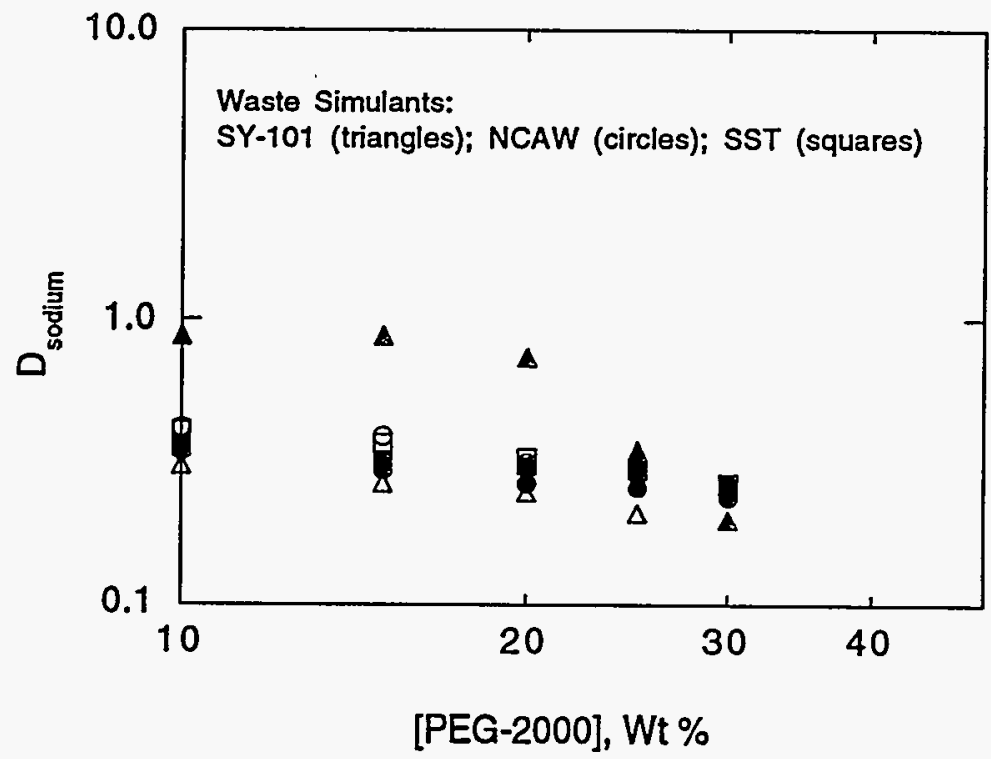

FIGURE 10 Partitioning of Sodium Between PEG-2000 and Waste Simulants as a Function of PEG Concentration at 25 (open symbols) and $50^{\circ} \mathrm{C}$ (filled symbols)

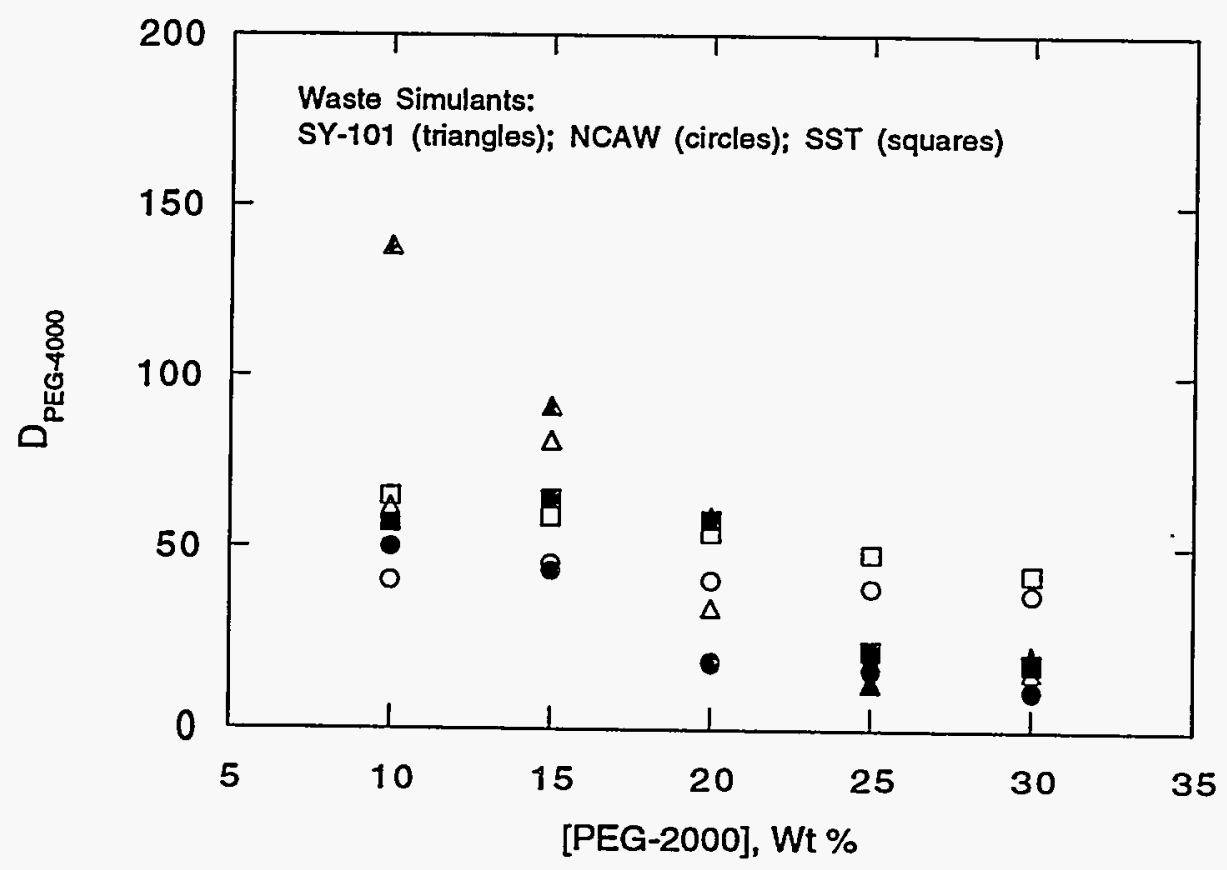

FIGURE 11 Partitioning of ${ }^{14} \mathrm{C}$-Labeled PEG-4000 as a Function of PEG Concentration at 25 (open symbols) and $50^{\circ} \mathrm{C}$ (filled symbols) 
exhibited the highest PEG distribution ratios at lower PEG concentrations, but $D$ values tailed off severely at higher concentrations, especially at $25^{\circ} \mathrm{C}$. The partitioning of PEG was essentially flat over the entire PEG- 2000 concentration range at $25^{\circ} \mathrm{C}$, but showed a pronounced decrease in partitioning at higher PEG-2000 concentrations in the NCAW and SST systems.

The molecular weight of PEG will affect its partitioning behavior if the polymer and the tank waste is diluted with water. The lower the dilution factor, the higher will be the polymer partition coefficient.

The measurement of the distribution ratios for labeled PEG was problematic. Initially, a substantial decrease in the PEG-4000 distribution ratios was observed with increasing PEG-2000 concentration. However, it was then established that the total number of counts (cpm) in the PEGrich phase decreased substantially with standing/counting time, probably as a result of separation of the PEG from the scintillation cocktail. This behavior was not observed in the salt-rich phase samples. This separation is not a problem when counting most radiotracers because they are dispersed in the cocktail, and appear to stay dispersed even after the PEG solution separates. However, when the tracer of interest is PEG itself, a decrease in counts with increasing time is observed. To remedy this problem, each PEG-rich phase sample was freshly vortexed immediately prior to counting, and a maximum count time of two minutes was used. Because of the relatively high distribution ratios and, hence, the large amount of activity in the PEG-rich phases, this shorter counting time did not adversely effect the counting statistics.

Ideally, the partition coefficient of PEG should be in the range of 1000 or higher to minimize polymer losses due to dissolution into the aqueous salt stream. It should be pointed out that the affinity between PEG and both nitrate and nitrite leads to low D values for PEG and enhances the partitioning of these anions into the $\mathrm{PEG}$ layer. This also has the undesirable result of reducing the separation factor between $\mathrm{TcO}_{4}{ }^{-}$and $\mathrm{NO}_{3}{ }^{-} \mathrm{NO}_{2}{ }^{-}$.

In Section 5 and 6 of this report, we discuss alternative ways to address these problems and, thereby, improve extraction performance. One approach involves immobilizing the PEG onto a solid support. This would completely eliminate polymer losses via dissolution. Another approach involves the use of a PPG in place of PEG. This polymer has a significantly lower water solubility than PEG and exhibits a higher extraction selectivity for $\mathrm{TcO}_{4}^{-}$.

\subsection{EXTRACTION SELECTIVITY}

We measured the extraction selectivity for $\mathrm{TcO}_{4}{ }^{-}$over the major electrolyte constituents of the tank wastes. The extractions were carried out by contacting $30 \mathrm{wt} \%$ solutions of PEG-1500 and PEG-3400 with equal volumes of undiluted waste simulants at 25 and $50^{\circ} \mathrm{C}$. The extraction behavior was expected to bracket that of the PEG-2000 system. 
Partition coefficients for the major electrolytes present in the tank wastes at 25 and $50^{\circ} \mathrm{C}$ are reported in Tables 3 and 4, respectively. In general, the D values for inorganic electrolyte species were depressed by either increasing temperature or increasing PEG molecular weight. The largest $D$ values were obtained for nitrate and nitrite - anions that do not support biphase formation with PEGs.

The D values shown in Tables 1-3 were used to calculate separation factors between pertechnetate and other waste simulant anions (see Table 5). It is evident that fairly high single-stage separation factors can be attained. In general, the separation factors between pertechnetate and multivalent anions were greater than those between pertechnetate and monovalent anions. The best separation was between $\mathrm{TcO}_{4}{ }^{-}$and $\mathrm{CO}_{3}{ }^{2-}$. The separation factors between pertechnetate and nitrate/nitrite were substantially lower. Nevertheless, with multi-stage, countercurrent extraction, it should be possible to achieve technetium decontamination factors well above $10^{3}$.

It is well known that the uranyl ion can form complexes with pertechnetate. Small amounts of uranium in the real tank wastes might lead to complexation of $\mathrm{TcO}_{4}{ }^{-}$and thereby significantly alter its partitioning. We investigated this possibility by measuring the $\mathrm{D}$ values of technetium in the presence of comparable concentrations of uranium. The concentration of ${ }^{99} \mathrm{Tc}$ used in the D-value measurements was approximately $9 \times 10^{-4} \underline{\mathrm{M}}$. Therefore, a uranium concentration of $10^{-4} \underline{\mathrm{M}}$ was used to study the effect of uranium on pertechnetate extraction. Under these conditions, the presence of uranyl ion had no significant effect on the partitioning of pertechnetate. Representative extraction data are shown in Table 6.

\subsection{EFFECT OF IRRADIATION}

An important consideration for the PEG-based extraction systems is the potential damage to the polymer system over long periods of time. To address this issue, the ABE systems were subjected to varying doses of radiation and then analyzed to identify degradation products and their effects on $\mathrm{TcO}_{4}{ }^{-}$partitioning. Actual tank waste solutions will expose the polymer extractant systems to $\beta$ and $\gamma$ radiation. For example, radiation exposure from SY-101 waste simulant corresponds to $\sim 5 \mathrm{Mrad}$ per year [Meisel]. Cesium and strontium are the source of $>99 \%$ of the $\beta$ and $\gamma$ radiation in the supernatant. Their removal from the supernatant prior to technetium extraction would significantly reduce the exposure of the polymer-rich phase to radiation.

We exposed aqueous PEG solutions to between 4 and 14 Mrad of $\gamma$ radiation, using the ${ }^{60}$ Co source at ANL (see Appendix B for experimental details). The only noticeable physical effect of the 14-Mrad irradiation dose was that a slight yellow color developed in the polymer phase on subsequent contact with the waste simulants. Decomposition products of the irradiated PEG solutions were analyzed by gas chromatography-mass spectrometry (GC-MS) and are listed in Appendix B. Major decomposition products of the PEGs were short chain alcohols, such as ethanol 
TABLE 3 Partition Coefficients of Constituent Electrolytes in Tank Waste Simulants at $25^{\circ} \mathrm{C}$

\begin{tabular}{lccccccccc}
\hline \multicolumn{1}{c}{ Biphase System } & $\mathrm{Na}^{+}$ & $\mathrm{K}^{+}$ & $\mathrm{Al}^{3+}$ & $\mathrm{NO}_{2}^{-}$ & $\mathrm{NO}_{3}^{-}$ & $\mathrm{SO}_{4}{ }^{2-}$ & $\mathrm{PO}_{4}{ }^{3-}$ & $\mathrm{F}^{-}$ & $\mathrm{CO}_{3}{ }^{2-}$ \\
\hline PEG-1500/SY-101 & 0.26 & - & 0.02 & 0.49 & 1.00 & - & - & - & 0.005 \\
PEG-1500/SST & 0.37 & 0.65 & 0.13 & 0.91 & 0.69 & 0.06 & $<0.13$ & 0.13 & 0.063 \\
PEG-1500/NCAW & 0.39 & 0.63 & 0.17 & 0.69 & 0.86 & 0.09 & 0.51 & 0.14 & 0.084 \\
PEG-3400/SY-101 & 0.24 & - & 0.01 & 0.45 & 0.73 & - & - & - & 0.004 \\
PEG-3400/SST & 0.32 & 0.60 & 0.07 & 0.55 & 0.72 & 0.03 & $<0.13$ & 0.11 & 0.030 \\
PEG-3400/NCAW & 0.32 & 0.59 & 0.07 & 0.61 & 0.83 & 0.03 & $<0.02$ & 0.13 & 0.031 \\
\hline
\end{tabular}

TABLE 4 Partition Coefficients of Constituent Electrolytes in Tank Waste Simulants at $50^{\circ} \mathrm{C}$

\begin{tabular}{lccccccccc}
\hline \multicolumn{1}{c}{ Biphase System } & $\mathrm{Na}^{+}$ & $\mathrm{K}^{+}$ & $\mathrm{Al}^{3+}$ & $\mathrm{NO}_{2}{ }^{-}$ & $\mathrm{NO}_{3}{ }^{-}$ & $\mathrm{SO}_{4}{ }^{2-}$ & $\mathrm{PO}_{4}{ }^{3-}$ & $\mathrm{F}^{-}$ & $\mathrm{CO}_{3}{ }^{2-}$ \\
\hline PEG-1500/SY-101 & 0.24 & - & 0.02 & 0.50 & 0.68 & - & - & - & 0.004 \\
PEG-1500/SST & 0.32 & 0.56 & 0.10 & 0.54 & 0.71 & 0.05 & $<0.13$ & 0.13 & 0.041 \\
PEG-1500/NCAW & 0.33 & 0.56 & 0.10 & 0.59 & 0.83 & 0.06 & 0.03 & 0.13 & 0.043 \\
PEG-3400/SY-101 & 0.20 & - & 0.01 & 0.36 & 0.67 & - & - & - & 0.002 \\
PEG-3400/SST & 0.30 & 0.56 & 0.05 & 0.48 & 0.65 & 0.02 & $<0.13$ & 0.07 & 0.025 \\
PEG-3400/NCAW & 0.30 & 0.53 & 0.05 & 0.52 & 0.76 & 0.03 & $<0.02$ & 0.11 & 0.019 \\
\hline
\end{tabular}

TABLE 5 Separation of Pertechnetate from Other Waste Simulant Anions Using PEG-3400 at $50^{\circ} \mathrm{C}$

\begin{tabular}{lc}
\hline \multicolumn{1}{c}{ Ionic Species } & Separation Factor \\
\hline $\mathrm{F}-$ & 171 \\
$\mathrm{NO}_{3}{ }^{-}$ & 79 \\
$\mathrm{NO}_{2}{ }^{-}$ & 147 \\
$\mathrm{SO}_{4}{ }^{2-}$ & 600 \\
$\mathrm{CO}_{3}{ }^{2-}$ & 26,500 \\
$\mathrm{PO}_{4}{ }^{3-}$ & $>700$ \\
\hline
\end{tabular}

a Calculated by dividing the $\mathrm{D}$ value for $\mathrm{TcO}_{4}{ }^{-}$by that for the other anions. 
TABLE 6 Extraction of Pertechnetate in the Presence of U(VI) at $50^{\circ} \mathrm{C}$

\begin{tabular}{lrr}
\hline & \multicolumn{2}{c}{ D Value, $\mathrm{TcO}_{4}^{-}$} \\
\cline { 2 - 3 } \multicolumn{1}{c}{ Biphase System } & No U(VI) & $10^{-4} \underline{\underline{M}}$ U(VI) \\
\hline PEG-1500/SY-101 & 46 & 42 \\
PEG-1500/SST & 9 & 9 \\
PEG-1500/NCAW & 9 & 9 \\
PEG-3400/SY-101 & 58 & 56 \\
PEG-3400/SST & 12 & 13 \\
PEG-3400/NCAW & 15 & 15 \\
\hline
\end{tabular}

and methanol. After a 14-Mrad exposure, no physical change was observed in the PEGs. Yet, as shown in Table 7, PEG-3400 partition coefficients with irradiated PEG were higher than with the nonirradiated polymer. The depressed partitioning of the PEG into the salt phase after irradiation may be the result of a decrease in the solubility of the PEG due to radiation-induced cross-linking. However, the viscosity of the irradiated PEG- 1500 solutions was not noticeably different from that of fresh PEG stock solutions, suggesting that only minimal cross-linkage had occurred.

In conjunction with studies of the direct radiolysis of the PEGs, we examined radiation effects on the partitioning of $\mathrm{TcO}_{4}^{-}$and carbonate species in the $\mathrm{PEG} /$ waste simulant systems. In the case of both PEG-1500 and PEG-3400, the degradation products from a radiation dose corresponding to about three years of exposure (14 Mrad) did not affect the extraction of pertechnetate or carbonate species between the PEG and waste simulant phases at 25 and $50^{\circ} \mathrm{C}$. Data in Table 8 shows that the extraction of pertechnetate was unaffected by irradiation.

\subsection{EXTRACTION OF IODINE}

We also examined the potential ability of $\mathrm{ABE}$ systems to remove iodine from caustic tank waste supernatant. In the absence of information on the speciation of iodine in tank wastes, we measured partition coefficients for both iodide and iodate (see Appendix A, Section 4.1 for experimental details). These values are reported in Table 9.

The partition data show that the extraction of iodide is favored over that of iodate. In both cases, the partition coefficients were relatively insensitive to PEG molecular weight and temperature. 
TABLE 7 Effect of 14 Mrad of Gamma Radiation on the Partitioning of PEG-3400

\begin{tabular}{lll}
\hline & \multicolumn{2}{c}{ D Value, PEG-3400 } \\
\cline { 2 - 3 } Waste Simulant & Pre-Irradiation & Post-Irradiation \\
\hline 25ㄷ & & \\
SY-101 & 59 & 92 \\
SST & 39 & 52 \\
NCAW & 31 & 43 \\
S0 C & & \\
SY-101 & & \\
SST & 56 & 96 \\
NCAW & 35 & 52 \\
\hline
\end{tabular}

TABLE 8 Effect of Gamma Radiation on the Extraction of Pertechnetate from Simulated Waste Solutions at $50^{\circ} \mathrm{C}$

D Value, $\mathrm{TcO}_{4}^{-}$

\begin{tabular}{lcc}
\multicolumn{1}{c}{ Biphase System } & No Irradiation & 14-Mrad-Dose \\
\hline PEG-1500/101-SY & 42 & 41 \\
PEG-1500/SST & 9 & 8 \\
PEG-1500/NCAW & 10 & 9 \\
PEG-3400/101-SY & 53 & 51 \\
PEG-3400/SST & 12 & 12 \\
PEG-3400/NCAW & 14 & 14 \\
\hline
\end{tabular}




\subsection{BACK EXTRACTION OF RADIONUCLIDES FROM PEG PHASES}

The stripping of pertechnetate and iodide from the loaded PEG-rich phase represents a major challenge in the development of aqueous biphasic separation systems for the treatment of supernatant solutions from the Hanford storage tanks. The challenge is to find a stripping method that is effective for both species and is also rapid, economical, environmentally benign, and simple enough so that scale-up is feasible. In addition, the stripping method must be compatible with longterm storage plans such as grouting.
TABLE 9 Extraction of Iodide and Iodate from SY-101 at 25 and $50^{\circ} \mathrm{C}$ by PEGs

\begin{tabular}{cccc}
\hline & & \multicolumn{2}{c}{$\mathrm{D}$ Values } \\
\cline { 3 - 4 } $\begin{array}{c}\text { Temperature, } \\
{ }^{\circ} \mathrm{C}\end{array}$ & Polymer & $\mathrm{I}^{-}$ & $\mathrm{IO}_{3}{ }^{-}$ \\
\hline \multirow{2}{*}{25} & 1500 & 5.02 & 0.26 \\
& 2000 & 5.29 & 0.23 \\
& 3400 & 5.36 & 0.25 \\
50 & 1500 & 4.83 & 0.25 \\
& 2000 & 4.50 & 0.31 \\
& 3400 & 4.84 & 0.44 \\
\hline
\end{tabular}

Several approaches, including reduction, complexation, precipitation, and ion exchange, were examined for their ability to back extract pertechnetate from the PEG-rich phase. However, most systems performed poorly, and, as in the case of reductive stripping of $\mathrm{TcO}_{4}^{-}$, the technetium was simply transferred into another high-ionic-strength salt phase. Clearly, economical approaches to the removal of dissolved species from the polymer-rich phase need to be developed. In an attempt to solve this problem, we examined the use of immobilized PEGs and other polymer systems that showed a potential for back extraction by means of a simple change in temperature. The results of these studies are described in Sections 5 and 6 of this report. 


\section{IMMOBILIZED POLYETHYLENE GLYCOL SYSTEMS}

Studies of pertechnetate extraction with immobilized PEGs were carried out by using commercially available resins from RAPP Polymere (Tubingen, Germany). The resins used were Tenta Gel SOH (TS-OH) and Tenta Gel SBr (TS-Br), which contain covalently bonded PEGs having terminal $-\mathrm{OH}$ and $-\mathrm{Br}$ groups, respectively. These resins have a macroporous polystyrene backbone with a PEG content of 70-80 wt\% and a bead diameter of $90 \mu \mathrm{m}$. These systems are of interest in that they combine certain extraction properties of the liquid/liquid PEG systems, with the elimination of polymer losses due to dissolution.

Pertechnetate partition coefficients of about 100 were obtained for the SST and NCAW waste simulant solutions at $25^{\circ} \mathrm{C}$ with TS-OH and TS-Br resins ( see Table 10). This partitioning behavior contrasted sharply with that of the SY-101 waste simulant, which had D values an order of magnitude lower than the other waste solutions.

A 1:1 dilution of the waste simulant solution prior to contact with the resin increased the $D$ value for the SY-101 waste simulant 10 -fold, yet it decreased the D value for both the SST and NCAW waste simulants to only a third of the original values. Increasing the equilibration temperature to $50^{\circ} \mathrm{C}$ had a similar effect to dilution for both resins. Partition coefficients greater than 200 were obtained with SY- 101 waste simulant at $50^{\circ} \mathrm{C}$, as opposed to approximately 10 at $25^{\circ} \mathrm{C}$. For the SST and NCAW waste streams, the partition coefficients of pertechnetate at $50^{\circ} \mathrm{C}$ were about a third lower than those at $25^{\circ} \mathrm{C}$ for both resins.

TABLE 10 Pertechnetate Extraction from Waste Simulants by Immobilized PEGs at 25 and $50^{\circ} \mathrm{C}$

\begin{tabular}{lcccc}
\hline & \multicolumn{5}{c}{ D Values } \\
\cline { 2 - 5 } & \multicolumn{2}{c}{$25^{\circ} \mathrm{C}$} & \multicolumn{2}{c}{$50^{\circ} \mathrm{C}$} \\
\cline { 2 - 5 } \cline { 3 - 5 } Waste Simulant & TS-OH & TS-Br & TS-OH & TS-Br \\
\hline \multirow{2}{*}{ SY-101 } & 6.0 & 10.6 & 290.7 & 248.3 \\
& $(77.0)^{\mathrm{a}}$ & $(91.4)$ & & \\
SST & 89.6 & 103.7 & 59.1 & 68.1 \\
& $(34.7)$ & $(35.8)$ & & \\
NCAW & 113.5 & 117.1 & 72.7 & 83.3 \\
& $(42.1)$ & $(43.2)$ & & \\
\hline
\end{tabular}

a Values in parentheses were obtained from 1:1 dilution of the waste simulants prior to extraction. 
One difference between SY-101 and the other waste simulants was the presence of a complexing agent, iminodiacetic acid (IDA), present at a concentration of approximately $0.2 \underline{\mathrm{M}}$. However, comparison of extractions from SY-101 prepared with and without IDA showed no significant difference in pertechnetate partitioning (see Table 11). The $\mathrm{D}$ values obtained for the SY-101 waste simulant without IDA were slightly lower than those obtained in the standard SY-101 waste solution.

Back extraction of technetium from the TS-OH and Ts-Br resins was examined as a function of temperature and sodium nitrate concentration. Our first observation was that the partitioning behavior of technetium on the TS-OH resin was independent of sodium nitrate concentration at $10^{\circ} \mathrm{C}$ (see Figure 12). At a sodium nitrate concentration of $1 \mathrm{M}$, similar D values were obtained for both resins. However, the partitioning of pertechnetate onto the TS-Br resin increased dramatically when the sodium nitrate concentration was lowered to $0.01 \underline{\mathrm{M}}$.

The extraction properties of the resins were also examined as a function of nitric acid concentration at $25^{\circ} \mathrm{C}$. The $\mathrm{D}$ values obtained for pertechnetate were approximately the same at 1.0 and $0.1 \underline{\mathrm{M}} \mathrm{HNO}_{3}$, but increased dramatically at $0.01 \underline{\mathrm{M}} \mathrm{HNO}_{3}$. Both the TS-OH and TS-Br resins showed the same trend, but much higher $\mathrm{D}$ values were obtained with the $\mathrm{Br}$-substituted polymer. Decreasing the temperature for the TS-Br resin resulted in an increase in the $\mathrm{D}$ values to.greater than 350 for the lowest nitric acid concentration (results not shown).

Finally, we examined the potential for back extraction of technetium from the TS-OH and $\mathrm{TS}-\mathrm{Br}$ resins into water. The equilibration temperature of the extraction system was varied between 5 and $80^{\circ} \mathrm{C}$ (see Figure 13). The lowest $\mathrm{D}$ values for both resins were obtained at $80^{\circ} \mathrm{C}$, but even at this temperature they were greater than one. The extraction properties of these resins differed

TABLE 11 Effect of IDA on Pertechnetate Extraction using Tenta Gel Resins at $25^{\circ} \mathrm{C}$

\begin{tabular}{lrr}
\hline & \multicolumn{2}{c}{ D Value, $\mathrm{TcO}_{4}^{-}$} \\
\cline { 2 - 3 } \multicolumn{1}{c}{ Waste Simulant } & TS-OH & TS-Br \\
\hline & & \\
SY-101 & 6.0 & 10.6 \\
SY-101 (without IDA) & 5.3 & -8.0 \\
$50 \%$ SY-101// ${ }_{2} 0$ & 77.0 & 91.4 \\
$50 \%$ SY-101 (without IDA) & 73.9 & 81.7 \\
\hline
\end{tabular}




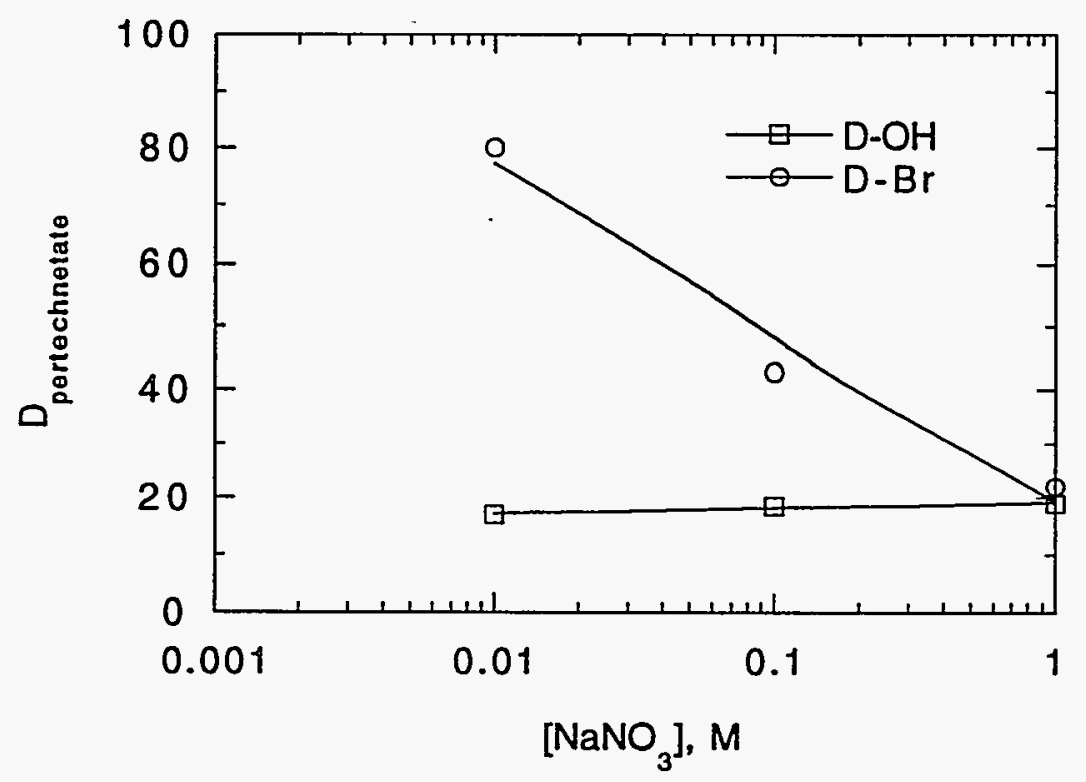

FIGURE 12 Partitioning of Pertechnetate onto TS-OH (squares) and TS-Br (circles) Resins as a Function of Sodium Nitrate Concentration at $10^{\circ} \mathrm{C}$

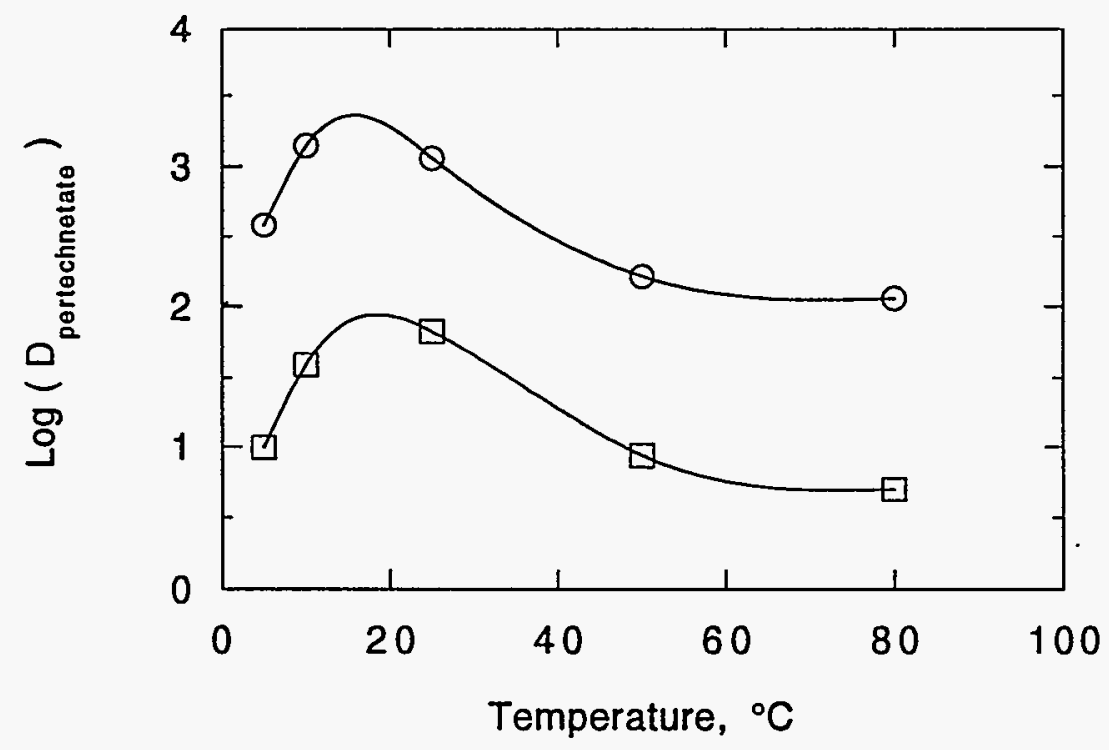

FIGURE 13 Partitioning of Pertechnetate onto TS-OH (squares) and TS-Br (circles) Resins from Deionized Water as a Function of Temperature 
markedly as a function of temperature. With TS-OH, the $\mathrm{D}$ values did not vary by more than a factor of ten (maximum $\mathrm{D}_{\mathrm{Tc}} \sim 65$ ) over the entire temperature range. By contrast, the $\mathrm{D}$ values for the $\mathrm{Br}$-substituted resin reached an estimated maximum of almost 1700 between 10 and $25^{\circ} \mathrm{C}$. Since $D$ values are largest when extracting from deionized water, scrubbing of the salts from the resins before stripping would yield high separation factors for $\mathrm{Tc}_{4}{ }_{4}^{-}$from the waste simulant components. However, regeneration of the resins and technetium recovery remains a problem. Fortunately, this is a case where a reductive stripping of technetium would lead to very little secondary waste generation since the need to maintain the aqueous biphase with a high-ionic-strength salt solution is eliminated. In addition, the TS-Br resin shows promise for removal of pertechnetate from groundwater. 


\section{POLYPROPYLENE GLYCOL EXTRACTION SYSTEMS}

In previous sections, we discussed the ability of PEGs to selectively extract pertechnetate from caustic nitrate/nitrite solutions; however, the efficiency of the $A B E$ process is limited by polymer losses due to dissolution into the salt-rich phase. Thus, in a search for enhanced selectivity and reduced polymer loss we examined other alkyl polyether alcohols that are less water soluble (more hydrophobic) than the PEGs. We measured pertechnetate extraction by a series of lowmolecular-weight polypropylene glycols (PPGs). Various parameters, including extraction kinetics, effects of polymer molecular weight, temperature, and back-extraction conditions, were examined.

\subsection{EXTRACTION OF PERTECHNETATE}

Characterization of the extraction kinetics for the PPG-425 system involved the measurement of pertechnetate partition coefficients between equal volumes of $50 \mathrm{wt} \%$ PPG- 425 and simulated SY-101 as a function of mixing time at 25 and $50^{\circ} \mathrm{C}$. The system equilibrated quickly (i.e., within $30 \mathrm{~s}$ ) at $25^{\circ} \mathrm{C}$, but at $50^{\circ} \mathrm{C}$, D values suddenly increased sharply between 5 and 10 mins. This peculiar jump in technetium extraction was observed in repeated measurements, indicating that the phenomenon is real. The $\mathrm{D}$ values for the partitioning of pertechnetate into the PPG phase decreased when the temperature was increased from 25 to $50^{\circ} \mathrm{C}$, suggesting that dehydration of the polymer inhibits pertechnetate extraction by alkyl polyethers. Comparison of the partitioning behavior of pertechnetate in the PPG and PEG systems (Table 12) indicates that PPG-425 provides much better extraction (D value was two times higher than that obtained with either PEG-1500 or PEG-3400 at $\left.25^{\circ} \mathrm{C}\right)$.

The data in Table 13 indicate that increasing polymer molecular weight (i.e., increasing hydrophobicity) leads to a reduction in the extraction of pertechnetate. The lowest molecular weight PPG examined (i.e., PPG-425) is slightly soluble in deionized water but is quite immiscible with sodium nitrate solutions of low ionic strength. On the other hand, the highest molecular weight PPG (i.e., PPG-4000) is very viscous and had to be diluted in dodecane to a final polymer concentration of $10 \mathrm{wt} \%$ for our experiment. Increasing the PPG- 4000 concentration in dodecane did not increase the $D$ value for pertechnetate and eventually resulted in the formation of a third liquid phase. The data in Table 13 clearly indicate that a high degree of polymer hydration is required for efficient pertechnetate extraction. This suggests that pertechnetate is extracted as a fully hydrated species.

Tables 14 and 15 list the partition coefficients for the major electrolyte species between the PPG phase and the waste simulants. The partition coefficients for nitrate ranged from $10^{-2}$ to $10^{-1}$ for PPG-425 (50 wt\% PPG-425/50 wt\% $\mathrm{H}_{2} \mathrm{O}$ ). The extraction of other anions such as, $\mathrm{Fl}^{-}, \mathrm{PO}_{4}{ }^{3-}$, and $\mathrm{SO}_{4}{ }^{2-}$ was below detection by ICA-AES. Partition coefficients with $100 \mathrm{wt} \%$ PPG-725 and PPG-1000 were at least an order of magnitude lower than with PPG-425, and D-values for $\mathrm{Al}^{3+}$ and 
TABLE 12 Comparison of Pertechnetate Extraction from SY101 Simulant by PEGs and PPG. 425 at $25^{\circ} \mathrm{C}$

\begin{tabular}{lc}
\hline & $\begin{array}{c}\text { Partition } \\
\text { Polymer System }\end{array}$ \\
\hline Coefficient, $\mathrm{TcO}_{4}^{-}$ \\
\hline 30\% PEG-1500 & 40 \\
30\% PEG-3400 & 50 \\
50\% PPG-425 & 75 \\
\hline
\end{tabular}

TABLE 13 Extraction of Pertechnetate from the SY-101 Simulant by PPGs at $25^{\circ} \mathrm{C}$

\begin{tabular}{lc}
\hline $\begin{array}{c}\text { PPG Molecular } \\
\text { Weight }\end{array}$ & $\begin{array}{c}\text { Partition } \\
\text { Coefficient, } \mathrm{TcO}_{4}^{-}\end{array}$ \\
\hline 425 & 95.5 \\
725 & 13.2 \\
1000 & 6.0 \\
$4000^{\mathrm{a}}$ & 0.00062 \\
\hline
\end{tabular}

a A 10 wt\% PPG-4000 in dodecane polymer solution was used instead of the undiluted polymer.

$\mathrm{F}^{-}$were below detection limits in most cases. Calculations of separation factors for $\mathrm{TcO}_{4}{ }^{-}$from $\mathrm{Na}^{+}$, $\mathrm{NO}_{3}{ }^{-}$, and $\mathrm{NO}_{2}{ }^{-}$indicate that PPG-725 and PPG-1000 provide greater selectivity for pertechnetate than does PPG-425 (see Table 16).

Partitioning data for pertechnetate between PPG-725 and the waste simulants at 25 and $50^{\circ} \mathrm{C}$ are given in Table 17. The partition coefficients for pertechnetate from all the waste simulants decreased as the temperature increased. As observed in the PEG extraction systems, the extraction of pertechnetate from SY-101 was consistently higher than that from the SST and NCAW waste simulants. 
TABLE 14 Partition Coefficient for Electrolytes with Various PPGs at $25^{\circ} \mathrm{C}$

\begin{tabular}{|c|c|c|c|c|c|c|}
\hline Polymer & $\begin{array}{c}\text { Waste } \\
\text { Simulant }\end{array}$ & $\mathrm{Na}^{+}$ & $\mathrm{K}^{+}$ & $\mathrm{Al}^{3+}$ & $\mathrm{NO}_{2}^{-}$ & $\mathrm{NO}_{3}^{-}$ \\
\hline \multirow[t]{3}{*}{ PPG-425 } & SY-101 & 0.033 & & $\mathrm{BDL}^{\mathrm{a}}$ & 0.037 & 0.081 \\
\hline & SST & 0.058 & 0.055 & 0.002 & 0.056 & 0.114 \\
\hline & NCAW & 0.046 & 0.046 & 0.002 & 0.048 & 0.105 \\
\hline \multirow[t]{3}{*}{ PPG-725 } & SY-101 & 0.004 & & $\mathrm{BDL}$ & 0.009 & 0.0037 \\
\hline & SST & 0.005 & 0.006 & $\mathrm{BDL}$ & 0.010 & 0.005 \\
\hline & NCAW & 0.004 & 0.005 & $\mathrm{BDL}$ & 0.009 & 0.003 \\
\hline \multirow[t]{3}{*}{ PPG-1000 } & SY-101 & 0.002 & . & BDL & 0.002 & 0.0049 \\
\hline & SST & 0.004 & 0.007 & BDL & BDL & 0.004 \\
\hline & NCAW & 0.003 & BDL & BDL & 0.002 & 0.005 \\
\hline
\end{tabular}

a Concentrations in PPG phase were below detection limit; $\mathrm{PO}_{4}{ }^{3-}$, $\mathrm{SO}_{4}{ }^{2-}$, and $\mathrm{F}$ concentrations were below detection limit in all applicable PPG phases.

TABLE 15 Partition Coefficient for Electrolytes with Various PPGs at $50^{\circ} \mathrm{C}$

\begin{tabular}{|c|c|c|c|c|c|c|c|}
\hline Polymer & $\begin{array}{c}\text { Waste } \\
\text { Simulant }\end{array}$ & $\mathrm{Na}^{+}$ & $\mathrm{K}^{+}$ & $\mathrm{Al}^{3+}$ & $\mathrm{NO}_{2}^{-}$ & $\mathrm{NO}_{3}^{-}$ & $F$ \\
\hline \multirow[t]{3}{*}{ PPG-425 } & SY-101 & 0.024 & & $\mathrm{BDL}^{\mathrm{a}}$ & 0.025 & 0.058 & \\
\hline & SST & 0.037 & 0.026 & 0.003 & 0.033 & 0.072 & BDL \\
\hline & NCAW & 0.030 & 0.026 & 0.021 & 0.029 & 0.069 & BDL \\
\hline \multirow[t]{3}{*}{ PPG-725 } & SY-101 & 0.002 & & BDL & 0.003 & 0.007 & - \\
\hline & SST & 0.003 & 0.005 & 0.002 & 0.005 & 0.007 & BDL \\
\hline & NCAW & 0.003 & 0.003 & 0.002 & $0.025^{-}$ & 0.006 & 0.009 \\
\hline \multirow[t]{3}{*}{ PPG-1000 } & SY-101 & 0.001 & & BDL & 0.014 & 0.003 & \\
\hline & SST & 0.002 & 0.005 & 0.001 & BDL & 0.003 & $\mathrm{BDL}$ \\
\hline & NCAW & 0.002 & 0.003 & 0.002 & 0.0015 & 0.003 & 0.010 \\
\hline
\end{tabular}

a Concentrations in PPG phase were below detection limit; $\mathrm{PO}_{4}{ }^{3-}$ and $\mathrm{SO}_{4}{ }^{2-}$ concentrations were below detection limit in all applicable PPG phases. 
TABLE 16 Separation of Pertechnetate from Other Electrolytes in SY-101 Simulant at $25^{\circ} \mathrm{C}$

\begin{tabular}{lrcc}
\hline & \multicolumn{3}{c}{ Pertechnetate Separation Factor } \\
\cline { 2 - 4 } Ionic Species & PPG-425 & PPG-725 & PPG-1000 \\
\hline & & & \\
$\mathrm{Na}^{+}$ & 2,273 & 3,300 & 3,000 \\
$\mathrm{Al}^{3+}$ & $\mathrm{BDL}^{\mathrm{a}}$ & $\mathrm{BDL}$ & $\mathrm{BDL}$ \\
$\mathrm{NO}_{3}^{-}$ & 926 & 3,568 & 1,224 \\
$\mathrm{NO}_{2}^{-}$ & 2,027 & 1,470 & $3,000^{-}$ \\
$\mathrm{CO}_{3}^{2-}$ & 2,778 & N.D. & N.D. \\
\hline
\end{tabular}

a Ion concentrations in PPG phases were below detection limit of ICP-AES.

TABLE 17 Partitioning of Pertechnetate between PPG-725 and Simulated Waste Solutions at 25 and $50^{\circ} \mathrm{C}$

\begin{tabular}{lcc}
\hline & \multicolumn{2}{c}{$\begin{array}{c}\text { Partition Coefficient, } \\
\mathrm{TcO}_{4}^{-}\end{array}$} \\
\cline { 2 - 3 } $\begin{array}{c}\text { Waste Simulant } \\
\text { Solution }\end{array}$ & $25^{\circ} \mathrm{C}$ & $50^{\circ} \mathrm{C}$ \\
\hline SY-101 & $13.2 \pm 0.4^{\mathrm{a}}$ & $4.22 \pm 0.19$ \\
SST & $8.9 \pm 0.2$ & $3.36 \pm 0.23$ \\
NCAW & $8.8 \pm 0.1$ & $2.97 \pm 0.04$ \\
\hline
\end{tabular}

a Standard deviation was based upon duplicate separation measurements. 


\subsection{BACK EXTRACTION FROM PPG PHASES}

Because of the highly selective extraction of pertechnetate by PPG-725, the partitioning behavior of this system was explored further. The agreement between forward and back extraction (see Table 18) indicates that the partitioning of pertechnetate reaches equilibrium rapidly. Mass balance calculations show almost complete accountability of technetium in the two liquid phases (see Table 18).

One of the advantages of the PPG extraction systems is the ability to regenerate the polymer phase by back extraction of pertechnetate into low-ionic-strength salt solutions. This is illustrated by the data in Table 19, which lists the partition coefficients for pertechnetate as a function of sodium nitrate concentration. These data suggest that deionized water would be capable of efficiently back extracting pertechnetate from a loaded PPG-725 phase.

TABLE 18 Partitioning of Pertechnetate between PPG.725 and $1 \underline{\mathrm{M}} \mathrm{NaNO}_{3}$ at $25^{\circ} \mathrm{C}$

\begin{tabular}{lcc}
\hline $\begin{array}{c}\text { Extraction } \\
\text { Step }\end{array}$ & $\mathrm{D}_{\mathrm{Tc}}\left(25^{\circ} \mathrm{C}\right)$ & $\mathrm{Tc}$ Mass Balance, \% \\
\hline Forward & $3.70 \pm 0.02^{\mathrm{a}}$ & $98.1 \pm 0.3$ \\
Back & $3.56 \pm 0.02$ & $96.9 \pm 1.5$ \\
\hline
\end{tabular}

a Standard deviation was based upon duplicate separation measurements.

TABLE 19 Partitioning of

Pertechnetate between

PPG-725 and Aqueous

Sodium Nitrate Solutions

\begin{tabular}{lc}
\hline & $\begin{array}{c}\text { Partition } \\
\text { Coefficient, } \\
\mathrm{TcO}_{4}^{-}\end{array}$ \\
\hline $\left.\mathrm{NaNO}_{3}\right], \underline{\mathrm{M}}$ & 0.49 \\
0.00 & 0.93 \\
0.01 & 1.28 \\
0.10 & 3.75 \\
1.00 & \\
\hline
\end{tabular}


We also carried out a series of back extraction measurements in which the polymer phases were first equilibrated with equal volumes of the waste simulants containing trace levels of pertechnetate. The loaded PPG phases were then scrubbed with deionized water through three cycles producing $\mathrm{D}$ values that were equal to or less than 0.40 (see Table 20).

The first contact of the loaded PPG phase with water yielded D values of about 1.2 for all three waste simulants. However, as the nitrate concentration is reduced below $0.01 \mathrm{M}$ (compare data in Tables 19 and 20), the $D$ values should rapidly drop below one. Because of the very low partition coefficients for nitrate and nitrite (i.e., $<0.01$ ), the concentrations of these salts in the polymer phase will be about $0.03 \underline{\mathrm{M}}$. These concentrations will be even lower if the tank wastes are diluted with water during their transfer from the tanks. Thus, the PPG phase can be regenerated at room temperature and without the need for chemical additives (e.g., reducing agents, complexants, etc.).

\subsection{EXTRACTION OF IODIDE}

The partitioning of iodide between PPG-725 and the three waste simulants was measured

using ${ }^{127} \mathrm{I}$-labeled sodium iodide. Partition coefficients, measured at 25 and $50^{\circ} \mathrm{C}$, are reported in Table 21. The partition coefficients for iodide in the PPG-725 systems are all about an order of magnitude lower than those from the PEG systems. They are, however, approximately 1-2 orders of magnitude greater than the respective $\mathrm{D}$ values for nitrate and nitrite.

To take full advantage of the extremely high separation factors between pertechnetate and the other tank waste constituents, it will be necessary to use a membrane contractor to eliminate other-phase-carryover, which is a phenomenon inherent in all dispersive-phase contractors such as pulsed columns, mixer-settlers, and centrifugal contractors. Membrane systems also permit efficient extraction at very high liquid flow ratios. Recent advances in module design offer significantly improved mass transfer over that available from conventional hollow-fiber designs [Ter Meulen]. Membrane contractors are also ideally suited for use with extraction systems such as the PPGs where the density difference between the process streams is less than 2-3\%. 
TABLE 20 Back Extraction of Pertechnetate from PPG-725 Phases Using Deionized Water at $25^{\circ} \mathrm{C}^{\mathrm{a}}$

\begin{tabular}{|c|c|c|c|}
\hline \multirow[b]{2}{*}{ Waste Simulant } & \multicolumn{3}{|c|}{$\begin{array}{l}\text { Partition Coefficient, } \\
\mathrm{TcO}_{4}^{-}\end{array}$} \\
\hline & $\begin{array}{c}1 \mathrm{st} \\
\text { Scrub }\end{array}$ & $\begin{array}{c}\text { 2nd } \\
\text { Scrub }\end{array}$ & $\begin{array}{c}3 \mathrm{rd} \\
\text { Scrub } \\
\end{array}$ \\
\hline SY-101 & 1.3 & 0.46 & 0.19 \\
\hline NCAW & 1.2 & 0.45 & 0.36 \\
\hline SST & 1.2 & 0.67 & 0.40 \\
\hline
\end{tabular}

a The PPG phase was previously equilibrated with the respective waste simulant containing trace levels of pertechnetate.

TABLE 21 Partitioning of Iodide between PPG-725 and Waste Simulant Solutions at 25 and $50^{\circ} \mathrm{C}$

\begin{tabular}{lcc}
\hline & $\begin{array}{c}\text { Partition } \\
\text { Coefficient, } \mathrm{I}^{-}\end{array}$ \\
\cline { 2 - 3 } Waste Simulant & $25^{\circ} \mathrm{C}$ & $50^{\circ} \mathrm{C}$ \\
\hline SY-101 & 0.33 & 0.11 \\
SST & 0.21 & 0.08 \\
NCAW & 0.14 & 0.04 \\
\hline
\end{tabular}




\section{ACKNOWLEDGMENTS}

This work was supported by the U.S. Department of Energy, Office of Technology Development, as part of the Efficient Separation and Processing Crosscutting Program, under contract W-31-109-ENG-38. The authors would like to thank D. Broczyk, E. Huff, and F. Smith, of the Analytical Chemistry Laboratory at ANL, for performing the ICP-AES Analyses, and some of the IC analyses; and A. Boparai and L. Chromizky for performing the analyses of PEG degradation products. 


\section{APPENDIX A: EXPERIMENTAL PROCEDURES}

\section{A.1 REAGENTS}

Polyethylene glycols (average $M W=1500,2000$, and 3400) and polypropylene glycols (average $M W=425,725,1000$, and 4000) were purchased from Aldrich and were used without further purification. The reagents used in preparing the waste simulant solutions were purchased from either Aldrich or Fisher. The following radiotracers were purchased from DuPont NEN and were used for partitioning measurements: ${ }^{14} \mathrm{C}$-labeled carbonate and ${ }^{3} \mathrm{H}$-labeled PEG-3400. .Technetium- 99 , as $\mathrm{NH}_{4} \mathrm{Tc}_{4}$ was obtained from the Nuclear Waste Technology Group, Chemical Technology Division, ANL. Stock solutions of this isotope were prepared as a $4.4 \times 10^{-5} \underline{\mathrm{M}}$ $(73.4 \mu \mathrm{Ci} / \mathrm{mL})$ solution in $0.5 \mathrm{M} \mathrm{NaOH}$.

\section{A.2 PREPARATION OF WASTE SIMULANTS}

Three tank waste simulants were used in this work: Hanford SY-101 supernatant, SST (single-shell tank) supernatant, and NCAW (neutralized current acid waste). The compositions of the waste simulants are given in Tables A-1 through A-3. The composition of a fourth tank waste simulant CC (complexant concentrate) is listed in Table A-4. No studies were performed with this simulant. We were able to prepare precipitate-free $\mathrm{CC}$ solutions at $60^{\circ} \mathrm{C}$ but if the solutions were allowed to cool to room temperature overnight, irreversible precipitation occurred. The precipitate volumes (about 2 vol\%) were large enough to render the simulant useless.

The tank wastes were prepared by adding reagents to heated $\left(90^{\circ} \mathrm{C}\right)$ water in the order in which they are listed in Tables A-1 through A-4. Because of the caustic nature of the simulants, either plastic or stainless steel labware was used.

To prepare SY-101, two slightly different procedures were used. For all experimental work except that involving PEG-2000, the SY-101 simulant was prepared by adding sodium hydroxide to about $120 \mathrm{~mL}$ of water, which was then maintained at $90^{\circ} \mathrm{C}$. The remaining reagents were added one at a time, with stirring. Sufficient time was allowed between reagent additions to ensure complete dissolution. Water was then added to give a volume of $250 \mathrm{~mL}$ at $90^{\circ} \mathrm{C}$. This produced a clear, but slightly yellow solution, which was then filtered through a pleated paper filter $(18.5-\mathrm{cm}$ diameter filter manufactured by Schleicher and Schuell and purchased from Baxter) into a 250-mL plastic volumetric flask. The solution was cooled to room temperature and deionized water added to the $250-\mathrm{mL}$ mark. All solutions were stored in plastic, screw-capped bottles. 
TABLE A-1 Composition of Hanford Tank SY-101 Supernatant ${ }^{\mathrm{a}}$

\begin{tabular}{lc}
\hline Reagent & Concentration, $\underline{\mathrm{M}}$ \\
\hline Sodium hydroxide & 2.00 \\
Sodium aluminate & 1.54 \\
Sodium nitrate & 2.59 \\
Sodium nitrite & 2.24 \\
Sodium carbonate & 0.42 \\
Citrate (trisodium salt) & 0.06439 \\
HEDTA (trisodium salt) & 0.03753 \\
EDTA (tetrasodium salt) & 0.03141 \\
IDA (disodium salt) & 0.18732 \\
\hline
\end{tabular}

a Recipe from [Colton].

TABLE A-2 Composition of SST-Supernatant ${ }^{\mathrm{a}}$

\begin{tabular}{lc}
\hline Reagent & Concentration, $\underline{\mathrm{M}}$ \\
\hline & 2.94 \\
Sodium nitrate & 0.46 \\
Sodium aluminate & 0.20 \\
Sodium nitrite & 0.05 \\
Sodium sulfate & 0.60 \\
Sodium bicarbonate & 0.0394 \\
Citrate (trisodium salt) & 0.0244 \\
EDTA (disodium salt) & 0.0771 \\
Potassium nitrite & 0.0058 \\
Sodium phosphate (tribasic) & 0.031 \\
Sodium fluoride & 1.96 \\
Sodium hydroxide & $7.4 \times 10^{-5}$ \\
Cesium nitrate &
\end{tabular}

a Recipe from [Colton]. 
TABLE A-3 Composition of NCAW

\begin{tabular}{lc}
\hline \multicolumn{1}{c}{ Reagent } & Concentration, $\underline{\mathrm{M}}$ \\
\hline & \\
Sodium nitrate & 0.31 \\
Sodium sulfate & 0.18 \\
Potassium nitrate & 0.14 \\
Rubidium nitrate & 0.00013 \\
Sodium carbonate monohydrate & 0.24 \\
Sodium nitrite & 0.52 \\
Sodium phosphate dibasic & 0.03 \\
Aluminum nitrate & 0.52 \\
Sodium fluoride & 0.107 \\
Sodium hydroxide & 4.08 \\
\hline
\end{tabular}

a Recipe from [Bray].

In the original recipes received from Hanford, the addition of sodium aluminate preceded sodium hydroxide. However, this order of addition does not result in complete dissolution of the aluminum.

Because of the caustic nature of the waste simulants, care must be taken in choosing filter papers. Standard filter papers (i.e., Whatman) can be dissolved by hot caustic solutions, and filtering at room temperature is inordinately slow. Westinghouse Hanford personnel suggested using a medium glass frit to filter waste simulant solutions [Colton]. However, there was concern that dissolution of silica and the formation of colloidal aluminosilicates would affect partitioning behavior in PEG/salt systems. All partitioning studies were carried out with paper-filtered waste simulants except for those involving PEG-2000, in which waste simulant solutions were filtered through glass frit filters.

All of the solutions that were filtered through a glass frit, produced some precipitate. SY-101 produced the largest amount of precipitate and appeared cloudy, whereas precipitation from NCAW and SST was negligible. In addition, when an aliquot of SY-101 was contacted with an equal volume of 40-60 wt\% PEG-2000 and left overnight, the PEG-rich phase solidified. This was probably due to contamination of the salt solutions with colloidal silica from the glass frit and its subsequent reactions with $\mathrm{PEG}$. All of the solutions filtered through paper were clear and precipitatefree when first prepared. Only after 2 to 3 days did a small amount of precipitate appear in the NCAW simulant. After the solution was centrifugated, it remained precipitate-free. Regardless of preparation technique, all waste simulant solutions were centrifuged prior to use. 
TABLE A-4 Composition of CC Simulant ${ }^{2}$

\begin{tabular}{lc}
\hline \multicolumn{1}{c}{ Reagent } & Concentration, $\mathrm{M}$ \\
\hline Sodium nitrate & 2.74 \\
Sodium sulfate & 0.1 \\
Potassium nitrate & 0.05 \\
Sodium carbonate & 0.75 \\
Sodium nitrite & 1.5 \\
Sodium phosphate (dibasic) & 0.03 \\
Aluminum nitrate & 0.5 \\
Calcium nitrate & 0.02 \\
Sodium floride & 0.15 \\
Sodium chloride & 0.1 \\
Sodium hydroxide & 3.46 \\
Ferric nitrate & 0.06 \\
Lanthanum nitrate & 0.001 \\
Magnesium nitrate & 0.01 \\
Manganese nitrate & 0.02 \\
Molybdic anhydride & 0.005 \\
Sodium silicate & 0.005 \\
Strontium nitrate & 0.0007 \\
Zinc nitrate & 0.002 \\
Zirconyl nitrate & 0.002 \\
EDTA (tetrasodium salt) & 0.03 \\
Citric acid & 0.064 \\
HEDTA (trisodium salt) & 0.038 \\
NTA (trisodium salt) & 0.0074 \\
Sodium gluconate & 0.30 \\
IDA (disodium salt) & 0.23 \\
\hline & \\
\hline
\end{tabular}

a Recipe from [Colton]. 


\section{A.3 MEASUREMENT OF PHASE DIAGRAMS AND PHASE SEPARATION RATES}

Phase diagrams for the PEG/waste simulants were determined by turbidimetric titration. For each titration sample, weighed aliquots of the PEG phase and the waste simulant were combined in a test tube and placed in a thermostated water bath. Water was gradually added while stirring until the turbid mixture became clear, then the final weight of the system was determined.

Phase separation times and dispersion numbers were determined by the following procedure. Equal aliquots of PEG-2000 and waste stock solution were placed in a flat-bottom test tube. The tube was vortexed for $2 \mathrm{~min}$ and placed in a thermostated water bath, and the time needed for phase disengagement to produce constant height interface was recorded. The dispersion number was calculated [Leonard-1981; Leonard-1983; Chaiko-1993A] as:

$$
\mathrm{N}_{\mathrm{Di}}=\frac{1}{t} \sqrt{\frac{\Delta z}{g}}
$$

where $\mathrm{N}_{\mathrm{Di}}$ is the dispersion number, $t$ is the phase separation time (s), $\Delta z$ is the total system height $(\mathrm{cm})$, and $g$ is the gravitational constant $\left(981 \mathrm{~cm} / \mathrm{s}^{2}\right)$. The phase separation times and dispersion numbers for the PEG/waste simulant systems are reported in Table A-5.

\section{A.4 MEASUREMENT OF PARTITION COEFFICIENTS}

Aqueous biphase extractions with PEG- 1500 and PEG-3400 were carried out by contacting equal volumes of the polymer phase with a salt or waste stream phase containing the radiotracer of interest. The polymer/salt solutions were mixed for 1 or $2 \mathrm{~min}$ using a vortexer to ensure complete mixing. This contact was followed by temperature-bath equilibration at 25 or $50^{\circ} \mathrm{C}$ for $5 \mathrm{~min}$. The samples were then centrifuged for 10 or $15 \mathrm{~min}$ and equilibrated for another $5 \mathrm{~min}$. Subsequently, the phases were separated and sampled. However, before sampling the phases from the PEG systems, they were diluted four-fold by weight with distilled water. In the case of the slightly-water-soluble PPG-425 systems, the polymer- and salt-rich phases were diluted four-fold by weight with an aqueous $0.1 \mathrm{wt} \%$ Triton X-100 solution. This surfactant was used to suppress the phase separation tendencies of PPG-425.

Cation and anion concentrations from PEG-1500 and PEG-3400 separation experiments were determined by inductively coupled plasma-atomic emission spectrometry (ICP-AES) and ion chromatography, respectively. Concentrations of other species were measured by using radiotracers of ${ }^{99} \mathrm{Tc},{ }^{3} \mathrm{H}$-labeled PEG-4000, or ${ }^{14} \mathrm{C}$-labeled carbonate, to determine concentrations of the isotopes in both phases. The activity present was measured by using a liquid scintillation spectrometer 
TABLE A-5 Phase Separation Times and Dispersion Numbers for the PEG-2000/Waste Simulant Systems at 25 and $50^{\circ} \mathrm{C}$

\begin{tabular}{|c|c|c|c|c|c|}
\hline \multirow{2}{*}{$\begin{array}{l}\text { Waste } \\
\text { Simulant }\end{array}$} & \multirow{2}{*}{$\begin{array}{c}\text { [PEG -2000], } \\
\text { wt\% }\end{array}$} & \multicolumn{2}{|c|}{$25^{\circ} \mathrm{C}$} & \multicolumn{2}{|c|}{$50^{\circ} \mathrm{C}$} \\
\hline & & time, $s$ & $\mathrm{~N}_{\mathrm{Di}} \times 10^{4}$ & time, $s$ & $\mathrm{~N}_{\mathrm{Di}} \times 10^{4}$ \\
\hline \multirow[t]{5}{*}{ SY-101 } & 10 & 128 & 2.9 & 22 & 17 \\
\hline & 20 & 195 & 1.9 & 30 & 12 \\
\hline & 30 & 254 & 1.4 & 40 & 9.0 \\
\hline & 40 & 345 & 1.1 & 47 & 8.1 \\
\hline & 60 & 370 & 1.0 & 55 & 7.0 \\
\hline \multirow[t]{5}{*}{ NCAW } & 10 & 56 & 6.8 & 20 & 18 \\
\hline & 20 & 80 & 4.7 & 20 & 18 \\
\hline & 30 & 105 & 3.6 & 25 & 15 \\
\hline & 40 & 150 & 2.5 & 31 & 12 \\
\hline & 60 & 210 & 1.8 & 45 & 8.0 \\
\hline \multirow[t]{5}{*}{ SST } & 10 & 52 & 7.3 & 20 & 18 \\
\hline & 20 & 80 & 4.7 & 20 & 18 \\
\hline & 30 & 110 & 3.4 & 25 & 15 \\
\hline & 40 & 140 & 2.7 & 32 & 11 \\
\hline & 60 & 210 & 1.7 & 42 & 8.1 \\
\hline
\end{tabular}

(Packard, Model 2500TR). Stock solutions of ${ }^{14} \mathrm{C}$-labeled PEG-4000, ${ }^{14} \mathrm{C}$-labeled $\mathrm{Na}_{2} \mathrm{CO}_{3}$, ${ }^{35} \mathrm{~S}$-labeled $\mathrm{H}_{2} \mathrm{SO}_{4}$, and ${ }^{32} \mathrm{P}$-labeled $\mathrm{H}_{3} \mathrm{PO}_{4}$ were prepared in distilled, deionized water, and the ${ }^{22} \mathrm{Na}^{+}$solution was prepared in dilute $\mathrm{HNO}_{3}$. The partition coefficient (or distribution ratio), $\mathrm{D}_{x}$, for a particular species, $\mathrm{x}$, is defined as the ratio of the concentration of the species in the less dense phase (usually the polymer-rich phase) to the concentration of the species in the more dense phase (usually the salt-rich phase).

The partitioning results for PEG-2000 from aqueous waste simulants (i.e., SY-101, SST, and NCAW) were investigated as a function of PEG-2000 concentration (20 to $60 \mathrm{wt} \%$ PEG-2000). For each system to be investigated, a biphasic system was prepared by mixing $1 \mathrm{~mL}$ of PEG-2000 stock solution of the appropriate concentration with $1 \mathrm{~mL}$ of an undiluted waste simulant. The systems were equilibrated by vortexing for $2 \mathrm{~min}$ followed by $2 \mathrm{~min}$ of centrifugation. A tracer quantity $(25 \mu \mathrm{L})$ of each radionuclide of interest was added to the equilibrated biphasic system followed by $2 \mathrm{~min}$ of vortexing and $2 \mathrm{~min}$ of centrifugation. The phases were then separated and placed into separate vials. Equal aliquots of each phase were removed for counting, and partition coefficients were calculated as described above. 


\section{A.4.1 Measurement of Iodine Partitioning}

Sodium iodide $(99.99+\%)$ and sodium iodate were purchased from Aldrich Chemical Company. To determine iodide concentration, samples were run through a Dionex DX-100 ion chromatograph using an IonPac AS12A analytical column (4 x $200 \mathrm{~mm}$ ). The eluent used was $22 \mathrm{mM}$ sodium carbonate/bicarbonate. The sodium carbonate (anhydrous) and sodium bicarbonate (anhydrous) were purchased from Fluka Chemical Company. To determine iodate concentration, the IC analyses were performed by using an IonPac AS12A analytical column. The eluent used was $5 \mathrm{mM}$ sodium tetraborate. The sodium tetraborate (99.9999\%) was purchased from Aldrich Chemical Company.

The partitioning of iodate and iodide between PEG and SY-101 was measured at 25 and $50^{\circ} \mathrm{C}$. The initial concentrations of iodate and iodide in the SY-101 waste simulant were 0.005 and $0.10 \underline{\mathrm{M}}$, respectively. Separate extraction experiments were performed so that the waste simulant contained either iodide or iodate, not both together. The extraction procedure was as follows:

- Equal volumes (i.e., $2 \mathrm{~mL}$ ) of SY-101 and $30 \mathrm{wt} \%$ PEG were added to plastic centrifuge tubes.

- The tubes were vortexed for $1 \mathrm{~min}$ and then equilibrated for $1 \mathrm{~min}$ in a thermostated water bath. This sequence was repeated five times. The tubes were then left for $15 \mathrm{~min}$ in the water bath to equilibrate.

- The samples were then centrifuged for $15 \mathrm{~min}$ and again left to equilibrate for $15 \mathrm{~min}$ in the thermostated water bath.

- The top and bottom phases were separated and placed in plastic vials.

- The phases were diluted appropriately with deionized water and analyzed by IC.

Some partition coefficient measurements were performed using ${ }^{127}$ I-labeled NaI (purchased from DuPont NEN). These measurements involved iodide partitioning between the various waste simulants and PPG-725.

\section{A.4.2 Partitioning to Immobilized PEGs}

Extractions with Tenta Gel resins were performed by weighing out 15 to $30 \mathrm{mg}$ of a resin into plastic centrifuge tubes. The solid was then contacted with $1 \mathrm{~mL}$ of an aqueous feed solution. The resin/salt solutions were mixed for $5 \mathrm{~min}$ and then equilibrated at the desired temperature in a 
water bath for $5 \mathrm{~min}$. The samples were then centrifuged for $5 \mathrm{~min}$ and the liquid phase was removed and filtered through a $0.02-\mu \mathrm{m}$ filter (Anotop, inorganic membrane) before sampling. The activity present was measured by using a liquid scintillation spectrometer (Packard, Model 2500 TR). The partition coefficient (or $\mathrm{D}$ value) for a particular species, $\mathrm{x}$ is defined as the ratio of the concentration of the species adsorbed $\left(C_{a}{ }^{x}\right)$ per unit mass of resin to the concentration of the species in the salt phase after the contact with the resin $\left(\mathrm{C}_{\mathrm{s}}{ }^{\mathrm{x}}\right)$ per unit volume of the solution:

$$
D_{x}=\frac{C_{a}^{x} / w}{C_{s}^{x} / V}
$$

where $w$ is the weight of resin and $\mathrm{V}$ is the equilibrium volume of liquid phase. Alternatively, this equation can be rewritten as:

$$
D_{x}=\frac{\left(C_{f}^{x}-C_{s}^{x}\right) / w}{C_{s}^{x} / V}
$$

where $C_{f}{ }^{x}$ is the concentration of species $x$ in the feed solution. 


\section{APPENDIX B: POLYMER IRRADIATION STUDIES}

The treatment of actual tank supernatants and salt cake would result in solvent exposure to significant radiation levels. Levels of $\beta+\gamma$ irradiation from major sources in the supernatant of tank SY-101 are approximately $1-2 \times 10^{-2} \mathrm{krad} / \mathrm{min}$ [Meisel]. Removal of ${ }^{137} \mathrm{Cs}$ and ${ }^{89 / 90} \mathrm{Sr}$ from the supernatant, before Tc extraction, would reduce the radiation exposure of the PEG solvent by approximately $99 \%$.

To assess potential solvent degradation problems, we irradiated solutions of PEG-1500, -2000 , and -3400 with 4 to $20 \mathrm{Mrad}$ of $\gamma$ radiation, using the ${ }^{60} \mathrm{Co}$ source at ANL. Two series of 30 wt\% PEG solutions were irradiated: aqueous PEG and PEG solutions that were equilibrated with an equal volume of the SY-101 simulant.

The irradiations were carried out at room temperature with the PEG solutions contained in loosely capped stainless steel beakers that were placed on a magnetic stirrer. During the course of the irradiation, the solutions were stirred to ensure an equal exposure throughout the entire solution volume. The radiation dose rate was measured using standard Fricke dosimeter solutions containing $1 \mathrm{mM} \mathrm{NaCl}$ [Allen]. After exposure, the PEG samples were freeze dried (to remove water and prevent further hydration) and stored in a desiccator under vacuum.

Two separate analyses were performed on the PEG samples. The first analysis was performed by using a purge and trap system for the analysis of volatile organic compounds, which is based on EPA method 8260 . The following instrumentation and gas chromatographic parameters were used:

Hewlett Packard 5890A Gas Chromatograph (GC)

Hewlett Packard 5970 Series Mass Selective Detector (MSD)

GC Capillary Column: DB624 30m x 0.53min ID

Injector temperature: $\quad 250^{\circ} \mathrm{C}$

Detector temperature: $\quad 250^{\circ} \mathrm{C}$

Oven temperature: Initial temperature: $10^{\circ} \mathrm{C}$ Initial time: $5 \mathrm{~min}$.

Rate: $6^{\circ} \mathrm{C} / \mathrm{min}$ Temp: $160^{\circ} \mathrm{C} \quad$ Hold time: $2 \mathrm{~min}$.

MSD Scan Range: $35-260$

Quantities of each of the detected compounds were estimated by using the internal standard compound 1,4-difluorobenzene and its extracted ion 114.0 atomic mass units (amu). The following calculation was used:

$$
\frac{\mathrm{Ax}}{\text { Aistd }} \times \frac{\mathrm{IS}(\mu \mathrm{g})}{\mathrm{RRF}} \times \frac{\mathrm{DF}}{\mathrm{V}_{0}}=\mu \mathrm{g} / \mathrm{L} \text { (parts per million) }
$$


where

$\mathrm{Ax}=$ The area count of the total ion chromatogram (TIC) for the detected compound.

Aistd $=$ Area count of internal standard 1,4-difluorobenzene extracted ion $114.0 \mathrm{amu}$.

IS = Number of nanograms of internal standard injected onto the column.

RRF = Relative response factor, assumed to be 1

$\mathrm{DF}=$ Dilution factor

$\mathrm{V}_{\mathrm{o}}=$ Amount of sample analyzed, $\mathrm{mL}$

Note: If there were interferences for a particular compound, then quantitation was based on the area count of an extracted ion.

The second analysis was performed with direct injection of the derivatized samples, using instrumentation designed for analysis of semivolatile organic compounds.

Hewlett Packard 5890 Series II Gas Chromatograph

Hewlett Packard 5970 Series Mass Selective Detector

GC Capillary Column: DB-5 $30 \mathrm{~m}$ x $0.25 \mathrm{~min} \mathrm{ID} \times 0.25$ micron

Injector temperature: $280^{\circ}$

Detector temperature: $280^{\circ}$

Oven temperature: Initial temperature: $35^{\circ} \mathrm{C}$ Initial time: $2 \mathrm{~min}$.

Rate: $6^{\circ} \mathrm{C} / \mathrm{min} \quad$ Temp: $200^{\circ} \mathrm{C} \quad$ Hold time: 0 min.

Rate: $15^{\circ} \mathrm{C} / \mathrm{min} \quad$ Temp: $280^{\circ} \mathrm{C} \quad$ Hold time: $2 \mathrm{~min}$.

MSD Scan Range 35-650

Each of the PEG samples was derivatized using a derivatizing agent with the trade name Tri-sil/BSA, as supplied by Pierce Chemical Company. The derivatizing agent contained 2.5 milliequivalent $/ \mathrm{mL}$ (1.25 mEq/mL for amides) $\mathrm{N}, 0$-bis(trimethylsilyl)acetamide (BSA) in silylation grade pyridine. The derivatization procedure involved adding approximately $10 \mathrm{mg}$ of the sample to $1 \mathrm{~mL}$ of the derivatizing agent. The mixture was heated in a water bath for approximately $20 \mathrm{~min}$ at 60 $70^{\circ} \mathrm{C}$.

For the analysis of the derivatized samples, data acquisition began at approximately 13 minutes into the chromatographic run. The reason for delaying data acquisition was the high levels of pyridine in the derivatizing agents, which, if allowed to contact it, would cripple the 
detector. To determine the identity of some of the earlier eluting peaks, one sample, PEG-1500 15-B1-1055-99, was diluted 100 times and data acquisition was begun at $4 \mathrm{~min}$.

The majority of the degradation products found in the irradiated PEG solutions belonged to the following classes: (a) alcohols, such as ethanol and its homologs-propanol, and butanol; (b) esters of acetic acid; (c) ketones, such as acetone; (d) cyclic ethers, such as dioxane and its derivatives; and (e) unknown compounds. These are compounds that would be expected to form upon breakage of the ether linkage of polyethylene glycol followed by oxidation to carbonyl compounds and to acids which in turn are esterified by alcohols present in the mixture.

Table B-1 lists the identification and concentrations of volatile organic compounds (VOCs) found in $30 \mathrm{wt} \%$ PEG-1500 and PEG-3400 solutions that received a $\gamma$-irradiation dose of $6 \mathrm{Mrad}$ at room temperature. The PEG phases were equilibrated with equal volumes of SY-101 simulant for $25 \mathrm{~min}$. The phases were separated just prior to the irradiations.

At higher $\gamma$-radiation doses, a greater variety of PEG degradation products was found (see Table B-2), but again, the degree of degradation was minimal and the majority of the products were present at concentrations less than $1 \mathrm{ppm}$.

Analysis of the derivatized PEG samples showed the presence of small amounts of high molecular weight compounds, most of which were also present in unirradiated PEG samples. The compounds that were unique to the irradiated PEG-1500 samples included: octadecanoic acid; 2, 2, 17,17-tetramethyl-3,6,9,13,16-pentaoxa-2,17-dislaoctadecone; and two other unidentifiable compounds present at concentrations similar to those of the two identified compounds. 
TABLE B-1 Identification of VOCs Generated in Aqueous PEG Solutions (30 wt\%) after a 6 Mrad Exposure to $\gamma$ Radiation at Room Temperature

\begin{tabular}{lcc}
\hline & \multicolumn{2}{c}{ VOC Concentration, PPM } \\
\cline { 2 - 3 } Degradation Product & PEG-1500 & PEG-3400 \\
\hline & & \\
Acetaldehyde & 0.31 & 0.43 \\
Ethanol & none detected & 0.15 \\
2-Propanone & 0.41 & 0.36 \\
2-Propanol & 0.42 & 0.24 \\
Unknown & 0.17 & 0.08 \\
\hline
\end{tabular}

TABLE B-2 Identification of VOCs Generated by $\gamma$ Irradiation of PEG-1500 Solutions (30 wt\%) at Doses of 0 and 20 Mrad

\begin{tabular}{lcc}
\hline & \multicolumn{2}{c}{ VOC Concentration, PPM } \\
\cline { 2 - 3 } \multicolumn{1}{c}{ Degradation Product } & 0 Mrad & 20 Mrad \\
\hline & & \\
Acetaldehyde & 15 & 47 \\
Ethanol & & 13 \\
2-Propanone & 0.43 & 1.8 \\
Formic acid, ethyl ester & & 2.2 \\
Fieran, 2-methyl & & 0.53 \\
1-Propanol & & 0.21 \\
Butanal & & 0.25 \\
2-Butanone & & 0.83 \\
Acetic acid, ethyl ester & & 2.4 \\
2-Butanol & & 0.42 \\
1,3-Dioxolane, 2-methyl & 0.59 \\
Acetic acid, 1-methylethyl ester & & 0.05 \\
2-Butenal & & 0.03 \\
Acetic acid, propyl ester & 0.17 \\
2, 4, 5-Trimethyl-1, 3-dioxolane & & 0.54 \\
Acetic acid, 2-methylpropyl ester & & 0.15 \\
Ethanone, 1-(2-fieranyl) & 0.25 \\
1,3-Dioxane, 2, 4-dimethyl & 0.02 \\
\hline
\end{tabular}




\section{REFERENCES}

\section{ALBERTSSON}

P.-A. Albertsson, Partition of Cell Particles and Macromolecules, 3rd Ed., WileyInterscience, New York (1986).

\section{ALLEN}

A.O. Allen, The Radiation Chemistry of Water and Aqueous Solution, Van Nostrand Co., Princeton (1961).

\section{ANANTHAPADMANABHAN}

K.P. Ananthapadmanabhan and E.D. Goddard, "Aqueous Biphase Formation in Polyethylene Oxide - Inorganic Salt Systems," Langmuir, $\underline{3}$, 25 (1987).

\section{ANDERS}

E. Anders, The Radiochemistry of Technetium, National Academy of Sciences, National Research Counsel, Report NAS-NS 3021, Washington, D.C. (1960).

\section{BLUMBERG}

A.A. Blumberg and J. Wyatt, "Poly(ethylene oxide)-Murcuric Halide Complexes," Polymer Letters, $\underline{4}, 653$ (1966).

BOYD

G.E. Boyd and Q.V. Larson, "Solvent Extraction of Heptavalent Technetium," J. Phys. Chem., 64, 988 (1960).

BRAY

L.A. Bray, Pacific Northwest Laboratory, Richland, WA, personal communication (1993).

CHAIKO-1993A

D.J. Chaiko, R. Mensah-Biney, C.J. Mertz and A.N. Rollins, "Beneficiation of Pu Residues by Ultrafine Grinding and Aqueous Biphasic Extraction," Sep. Sci. Technol., 28, 765 (1993).

\section{CHAIKO-1993B}

D.J. Chaiko, R. Mensah-Biney, and E. VanDeventer, "Soil Decontamination by Aqueous Biphasic Extractions," Removal of Uranium from Uranium Contaminated Soils Phase1: BenchScale Testing, Oak Ridge National Laboratory Report ORNL-6762 (1993).

COLTON

N.G. Colton, Pacific Northwest Laboratory, Richland, WA personal communication (1993). 
DOE

United States Department of Energy Final Environmental Impact Statement - Disposal of Hanford Defense High-Level, Transuranic, and Tank Wastes, U.S. DOE Report DOE/EIS-0113, Richland, WA (1987).

IWAMOTO

R. Iwamoto, Y. Saito, H. Ishihara, and H. Todakoro, "Structure of Poly(ethylene oxide) Complexes. II. Poly(ethylene oxide) Mercuric Chloride Complex," J. Polymer Sci., Part A-2, 1509 (1968).

KOLARIK

Z. Kolarik, Separation of Acinides and Long-Lived Fission Products from High-Level Radioactive Wastes (A. Review), Report KfK 4945, Institut fur Heisse Chemie, Karlsruhe (1991).

\section{KUPFER}

M.J. Kupfer, Preparation of Nonradioactive Substitutes for Radioactive Wastes, Rockwell Hanford Report DOE/ET/41900-S, Richland, WA (1981).

LEONARD-1981

R.A. Leonard, G.J. Bernstein, R.H. Pelto, and A.A. Ziegler, "Liquid-Liquid Dispersion in Turbulent Couette Flow," AIChEJ., 27, 495 (1981).

\section{LEONARD-1983}

R.A. Leonard, R.W. Bane, M.J. Steindler, R.A. Wigeland, and A.A. Ziegler, "Operation with 3 Liquid Phases in a Staged Liquid-Liquid Contactor," Sep. Sci. Technol., 18, 1563 (1983).

\section{LUNDBERG}

R.D. Lundberg, F.E. Bailey, Jr., and R.W. Callard, "Interactions of Inorganic Salts with Poly(ethylene oxide)," J. Polymer. Sci., Part A-1,ㅆ, 1563 (1966).

MEISEL

D. Meisel, H. Diamon, E.P. Horwitz, C.D. Jonah, M.S. Matheson, M.C. Sauer, Jr., J.C. Sullivan, F. Barnabas, E. Cerny, and Y.D. Cheng, Radiolytic Generation of Gases from Synthetic Waste, Argonne National Laboratory Report ANL-91/41 (1991).

SCHULTZ

W.W. Schultz, Cyclohexanone Solvent Extraction of ${ }^{99} \mathrm{TcO}_{4}$ From Alkaline Nuclear Waste Solutions, Rockwell International Report RHO-SA-123, Richland, WA (1980). 


\section{SNYDER}

S.M. Snyder, K.D. Cole, and D.C. Szlag, "Phase Compositions, Viscosities, and Densities for Aqueous Two-Phase Systems Composed of Polyethylene Glycol and Various Salts at $25^{\circ}$ C," J. Chem. Eng. Data, 37, 268 (1992).

\section{STRAALSUND}

J.L. Straalsund, J.L. Swanson, E.G. Baker, J.J. Holmes, E.O. Jones, and W.L. Kuhn, Clean Option: An Alternate Strategy for Hanford Tank Waste Remediation, Pacific Northwest Laboratory Report PNL-8388 Vol. 1, Richland, WA (1992).

\section{SWANSON}

'J.L. Swanson, Clean Option: An Alternate Strategy for Hanford Tank Waste Remediation, Pacific Northwest Laboratory Report PNL-8388 Vol. 2, Richland, WA (1993).

\section{TER MEULEN}

B.P. Ter Meulen, "Transfer Device for the Transfer of Matter and/or Heat from One Medium Flow to Another Medium Flow," U.S. Patent 5,230,796 (1993).

\section{ZVAROVA}

T.I. Zvarova, V.M. Shkinev, B. Ya. Spivakov, and Yu.A. Zolotov, "Liquid Extraction in the System Aqueous Salt Solution - Aqueous Polyethylene Glycol Solution," Dokl. Akad. Nauk SSSR, 273, 107 (1983). 
Distribution for ANL-95/39

Internal:

J. K. Bates

J. E. Battles

N. J. Beskid

D. L. Bowers

D. J. Chaiko (10)

J. C. Cunnane

J. S. Devgun

J. E. Harmon
J. E. Helt

J. L. Henriksen

T. R. Krause

J. J. Laidler

C. C. McPheeters

W. A. Mego

C. J. Mertz
K. M. Myles

D. T. Reed

M. J. Steindler

C. E. Till

G. F. Vandegrift

Y. Vojta

TIS Files

External:

DOE-OSTI (2)

ANL-E Library (2)

ANL-W Library

Manager, Chicago Operations Office, DOE

J. Haugen, DOE-CH

S. L. Webster, DOE-CH

Chemical Technology Division Review Committee Members:

E. R. Beaver, Monsanto Company, St. Louis, MO

D. L. Douglas, Consultant, Bloomington, $\mathrm{MN}$

R. K. Genung, Oak Ridge National Laboratory, Oak Ridge, TN

J. G. Kay, Drexel University, Philadelphia, PA

G. R. St. Pierre, Ohio State University, Columbus, $\mathrm{OH}$

J. Stringer, Electric Power Research Institute, Palo Alto, CA

J. B. Wagner, Arizona State University, Tempe, AZ

M. G. Adamson, Lawrence Livermore National Laboratory, Livermore, CA

J. Apple, Westinghouse Hanford Company, Richland, WA

J. A. Apps, Lawrence Berkeley Laboratory, Berkeley, CA

L. R. Avens, Los Alamos National Laboratory, Los Alamos, NM

G. S. Barney, Westinghouse Hanford Operations, Richland, WA

C. A. Barrington, Westinghouse Hanford Company, Richland, WA

E. Barth, U.S. Environmental Protection Agency, Cincinnati, OH

J. D. Berger, Westinghouse Hanford Company, Richland, WA

N. R. Brown, USDOE, Richland Operations Office, Richland, WA

T. Burford, Sandia National Laboratories, Albuquerque, NM

J. L. Burnett, USDOE, Office of Basic Energy Sciences, Germantown, MD

B. J. Carlson, Advanced Recovery Systems, Erwin, TN

T. D. Cooper, Westinghouse Hanford Company, Richland, WA

J. L. Cox, Pacific Northwest Laboratory, Richland, WA

W. R. Dworzak, Los Alamos National Laboratory, Los Alamos, NM 
M. Eagle, U.S. Environmental Protection Agency, Washington, DC

C. W. Francis, Oak Ridge National Laboratory, Oak Ridge, TN

C. W. Frank, USDOE, Office of Technology Development, Washington, DC

T. Fryberger, USDOE, Office of Technology Development, Germantown, MD

R. Gilchrist, Westinghouse Hanford Company, Richland, WA

H. Gold, Foster-Miller, Inc., Waltham, MA

D. Gombert, Lockheed Idaho Technology Company, Idaho Falls, ID

W. Gray, Pacific Northwest Laboratories, Richland, WA

J. Hart, USDOE, FUSRAP, Oak Ridge, TN

P. Hart, USDOE, Morgantown Energy Technology Center, Morgantown, WV

T. A. Hatton, Massachusetts Institute of Technology, Cambridge, MA

J. Hyde, USDOE, Office of Technology Development, Washington, DC

N. Jacob, Advanced Recovery Systems, Erwin, TN

W. L. Kuhn, Pacific Northwest Laboratory, Richland, WA

D. E. Kurath, Pacific Northwest Laboratory, Richland, WA

S. Leffler, Nuclear Remediation Technologies, San Diego, CA

H. L. Lomasney, ISOTRON, New Orleans, LA

G. J. Lumetta, Pacific Northwest Laboratory, Richland, WA

M. Malone, USDOE, Office of Technology Development, Germantown, MD

J. S. McCormack, Westinghouse Hanford Company, Richland, WA

C. P. McGinnis, Oak Ridge National Laboratory, Oak Ridge, TN

B. A. Moyer, Oak Ridge National Laboratory, Oak Ridge, TN

A. C. Muscatello, LATO Office, Rocky Flats Plant, Golden, CO

R. M. Orme, Westinghouse Hanford Company, Richland, WA

J. Paladino, USDOE, Office of Technology Development, Germantown, MD

M. Palmer, Los Alamos National Laboratory, Los Alamos, NM

W. M. Polansky, USDOE, Division of Advanced Energy Projects, Germantown, MD

C. Purdy, USDOE, Office of Technology Development, Germantown, MD

B. Roal, Westinghouse Hanford Company, Richland, WA

R. D. Rogers, Northern Illinois University, DeKalb, IL

B. Salley, Westinghouse Hanford Company, Richland, WA

M. J. Schliebe, Westinghouse Hanford Operations, Richland, WA

B. Schwinkendorf, BDM Federal, Albuquerque, NM

J. D. Sheppard, USDOE, Portsmouth Enrichment Office, Piketon, $\mathrm{OH}$

B. F. Smith, Los Alamos National Laboratory, Los Alamos, NM

R. Swatzell, Hazardous Waste Remedial Actions Program, Oak Ridge, TN

L. Tavlarides, Syracuse University, Syracuse, NY

G. Van Sickle, Bechtel Hanford, Inc., Richland, WA

V. Van Brunt, University of South Carolina, Columbia, SC

R. E. Vandercook, Westinghouse Hanford Company, Richland, WA

S. Warren, USDOE, Office of Environmental Restoration, Germantown, MD

J. Watson, Oak Ridge National Laboratory, Oak Ridge, TN

R. M. Wham, Oak Ridge National Laboratory, Oak Ridge, TN

K. Suzuki, JGC Corporation, JAPAN

M. Takeuchi, Japan Nuclear Fuel Limited, Tokyo, JAPAN 